\title{
Long-term axial capacity of deepwater jetted piles
}

\author{
A. ZAKERI*, E. LIEDTKE* , E. C. CLUKEY* and P. JEANJEAN*
}

\begin{abstract}
Jetting is a technique commonly used to install well conductors, which is faster than the conventional drill and cement method. Conductors are designed to support the buoyed weight of the first string of casings (typically, 3-5 days after jetting) and later to provide the lateral stability for the well system against cyclic loading from environmental elements. The axial bearing capacity of a jetted conductor increases with time due to consolidation and thixotropy effects; however, the field data for set-up only extend to about 10 days. Installation of jetted conductors as piles and anchors may be an economic solution for offshore developments. The long-term axial capacity of jetted conductors was investigated through a series of centrifuge modelling and laboratory thixotropy testing. The centrifuge tests simulated jetting installation of four model conductors and measured capacities at set-up times ranging between 10 and 1000 days in a kaolin clay seabed with an undrained shear strength profile similar to that encountered in deepwater Gulf of Mexico. The centrifuge test results were compared to the field data in the Gulf of Mexico. The implications of the centrifuge test results for deepwater Gulf of Mexico conditions are discussed. A method is presented for estimating the long-term axial capacity of jetted conductors in Gulf of Mexico seabed conditions with recommendations for additional studies.
\end{abstract}

KEYWORDS: anchors; centrifuge modelling; laboratory tests; offshore engineering; piles

\section{INTRODUCTION}

Deepwater oil and gas wells are drilled from anchored or dynamically positioned drill rigs. Exploration and appraisal wells are drilled to determine the presence of hydrocarbons and to evaluate the size, quantity and extent of a potential field. Development wells include production wells to extract hydrocarbons and water injection wells to enhance the production and/or to dispose of fluid bi-products. Both types of wells comprise a series of concentric steel pipes called casing strings that are telescopically drilled into the seabed to facilitate penetration of the final testing or production string.

A drilling vessel may have to be on standby for a couple of days during the operation. For some offshore developments in the Gulf of Mexico (GoM), taking advantage of the standby rig to install jetted conductors for use as permanent foundations (piles) later in the project may have economic benefits over more conventional deep foundations such as suction caissons or driven piles. Determining the axial capacity of jetted piles is based on the same geotechnical principles of jetted conductors for landing of the first string of casings. For well applications, the jetted conductor axial capacity is only needed for a short time (i.e. a few hours) and axial loading generally occurs a few days after installation. While the field data indicate the axial capacity of a jetted conductor continues to increase with time, they pertain only to the short-term performance of conductors, whereas the long-term capacity is of interest for jetted piles.

To that end, a study was initiated with the objectives of investigating the set-up characteristics of jetted piles and developing a design methodology to evaluate the long-term capacity of a jetted pile beyond the 10-day limit of the existing database in the GoM. These objectives were

Manuscript received 23 January 2014; revised manuscript accepted 30 September 2014.

Discussion on this paper closes on 1 May 2015, for further details see p. ii.

* Upstream Engineering Centre, BP America Inc., Houston, Texas, USA. achieved through a series of centrifuge modelling and laboratory testing. The latter was conducted on GoM clay samples to evaluate the contribution of thixotropy in developing the axial capacity. The results of the centrifuge and thixotropy tests are presented herein and compared to the existing field data in GoM. Finally, a method is presented to estimate the long-term axial bearing capacity of a jetted pile. In the absence of additional studies, this method may be applied to jetted piles installed in deepwater GoM.

\section{WELL DESIGN AND JETTING OPERATION}

Figure 1 schematically illustrates configuration of a typical exploration well below the mudline. The spaces between the annulus of the casings are cemented. The first string of well casing or pipes is called a surface conductor or a structural casing. Deepwater conductors typically range from 0.76 to $0.91 \mathrm{~m}$ (30 to 36 inches) in outer diameter (OD) with a wall thickness of $38 \cdot 1$ to $50 \cdot 8 \mathrm{~mm}$ ( 1.5 to 2 inches). Larger sizes may also be used depending on the well design requirements. The main functions of a conductor are

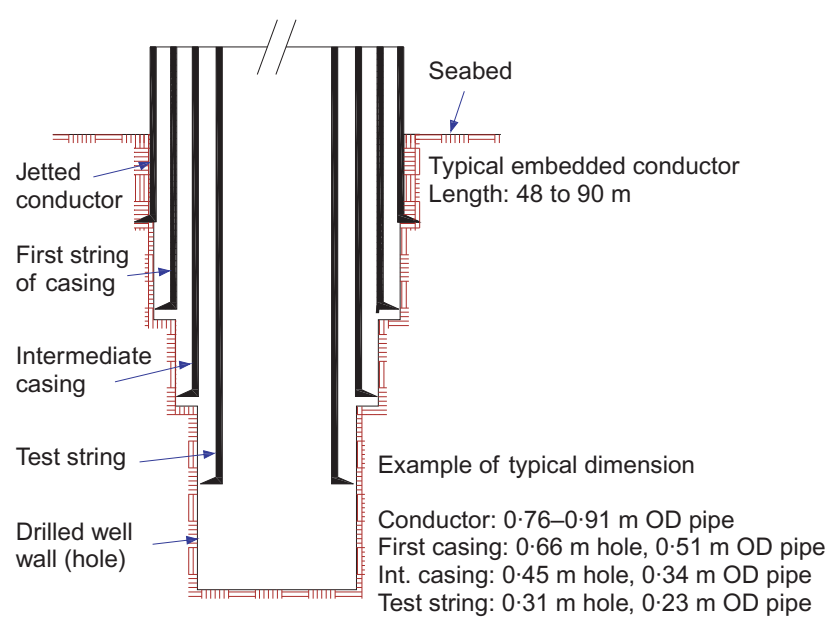

Fig. 1. Typical exploration well casings below the mudline 
(a) to stabilise and to protect the near-surface sediments from collapse and fracturing under mud pressures during the initial top-hole drilling operation

(b) to resist the buoyed weight of the first string of casings (surface casing), which is landed shortly after installation of the conductor

(c) later as a composite system with the surface casing, to provide the lateral stability for the well system and the blowout preventer (BOP) against the cyclic and tensile loading from the vessel motions and the riser oscillations driven by the environmental elements.

Jetting is a technique commonly used to install well conductors in deepwater environments. When properly performed, it is faster than the conventional drill and cement method. Jetting of structural casing has become the preferred method of installation in most deepwater environments such as the GoM, offshore Angola, Brazil and Egypt. The history of jetting can be traced back to the 1960 s, when a combination of drive-jetting procedures was used to install conductors (approximately $30 \mathrm{~m}$ long, $0.75 \mathrm{~m}$ in diameter, $25 \mathrm{~mm}$ thick) for 55 wells in the GoM in water depths ranging between 38 and $131 \mathrm{~m}$ (Minton, 1967). In the 1970s, development of tools such as the positive displacement mud motor and the wellhead housing running tool allowed the jetting technique to evolve (Akers, 2008). Today, jetting is successfully performed in water depths well in excess of $1500 \mathrm{~m}$ (Evans et al., 2002; Jeanjean, 2002).

Jetting involves fully assembling the entire length of a conductor sections, drill-ahead tool, drill bit and drill pipes and then wash-boring the conductor into place with seawater and occasionally high-viscosity 'mud' sweeps injected through the drill bit. Often multiple reciprocations are needed to reach the target depth. Soft clays are suitable for jetting. Fig. 2 illustrates the drilling components that go inside a conductor, the so-called 'bottom hole assembly'

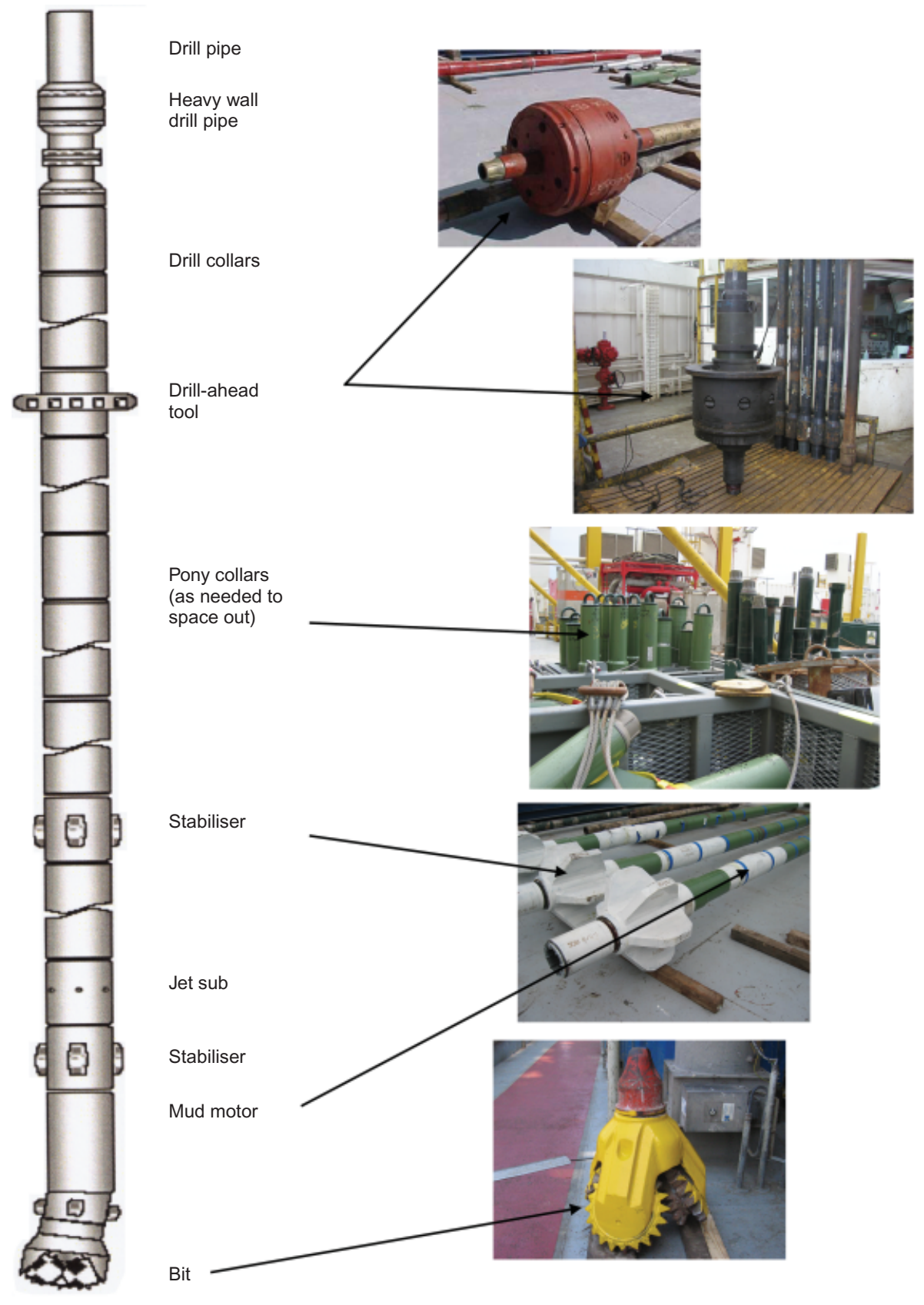

Adopted from TRI City Services

Fig. 2. Drilling components to be housed inside a conductor - bottom hole assembly (BHA) 


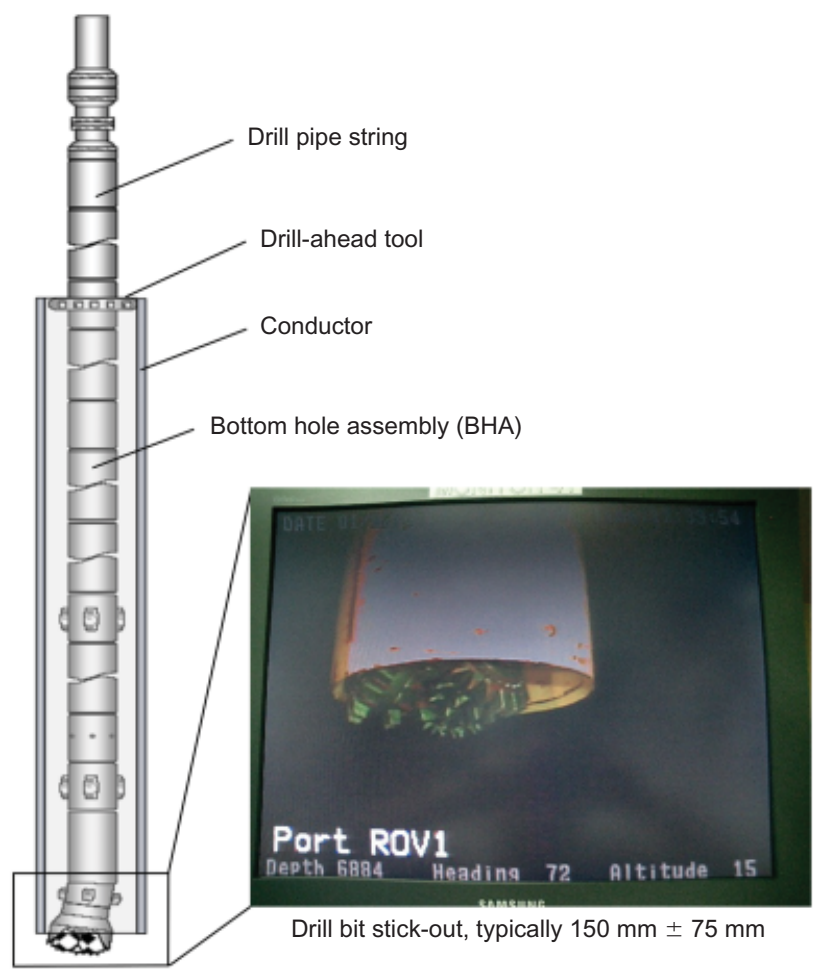

Fig. 3. Jetting assembly: a BHA installed inside a conductor and ready for jetting operation

(BHA). Fig. 3 shows a BHA rigged inside a conductor (jetting assembly) and ready for jetting operation. Once fully rigged, the whole assembly is then lowered to the seabed. Upon a gentle touchdown, the jetting assembly is allowed to penetrate into the seabed under the self-weight. After initial penetration the water pumps are turned on to aid in the installation. At the end of the self-weight penetration further penetration to the target depth is achieved by reciprocating the conductor in order to temporarily reduce the soil resistance along the outside wall of the conductor.

The weight that can be slacked off to assist penetration is limited by the need to maintain tension in the drill pipe above the mudline. This weight is referred to as the weighton-bit (WoB), and is constantly monitored throughout the operation to ensure the drill pipe above the mudline always remains in tension. The $\mathrm{WoB}$ is usually recorded in the Imperial unit of kilo pounds-force (kips). The criteria for the maximum and minimum allowable WoB may vary among the different operators. For example, BP's recommendation is that the final $\mathrm{WoB}$ should be $80 \%$ of the weight of the BHA and conductor assembly and that a narrow band defining the recommended minimum and maximum WoB should be used during jetting. The above criteria have been exemplified in Fig. 4.

The water flow rate and the jetting pressure at the conductor shoe (the so-called static standpipe pressure (SSP)) are also measured throughout the operation. The jetting pressure is relative to atmosphere and varies to overcome the hydrostatic pressure from the water column. The water flow rate is essentially the pump flow rate at the bit which flows upward inside the conductor assembly and is discharged above the mudline. During jetting of the first one-third of conductor length, the flow rates and corresponding pressures normally start with a low value and gradually increase to the target value. The target values for these two parameters may vary widely among the rig operators. The objective is to achieve an acceptable penetration rate while minimising damage to the foundation soils that could significantly affect the set-up and to prevent the conductor from broaching or plugging during the operation. Broaching is caused by a restriction inside the conductor such as pack-off around the jetting BHA or plugging of the exit ports in the wellhead and running tool (Akers, 2008). If broaching occurs inside the conductor, the water makes an alternative path and flows outside the conductor towards the mudline (i.e. path of least resistance) and the desired axial capacity may not be achieved. Particular care is taken when jetting the last onethird of the conductor where the largest contribution to the axial capacity is gained. In GoM, the magnitudes for water flow rate and SSP could typically range between about 3000 and $6500 \mathrm{l} / \mathrm{min}$ (800 to 1700 gallon/min), and 8200 and $20500 \mathrm{kPa}$ (1189 and $2973 \mathrm{psi})$, respectively. In summary,

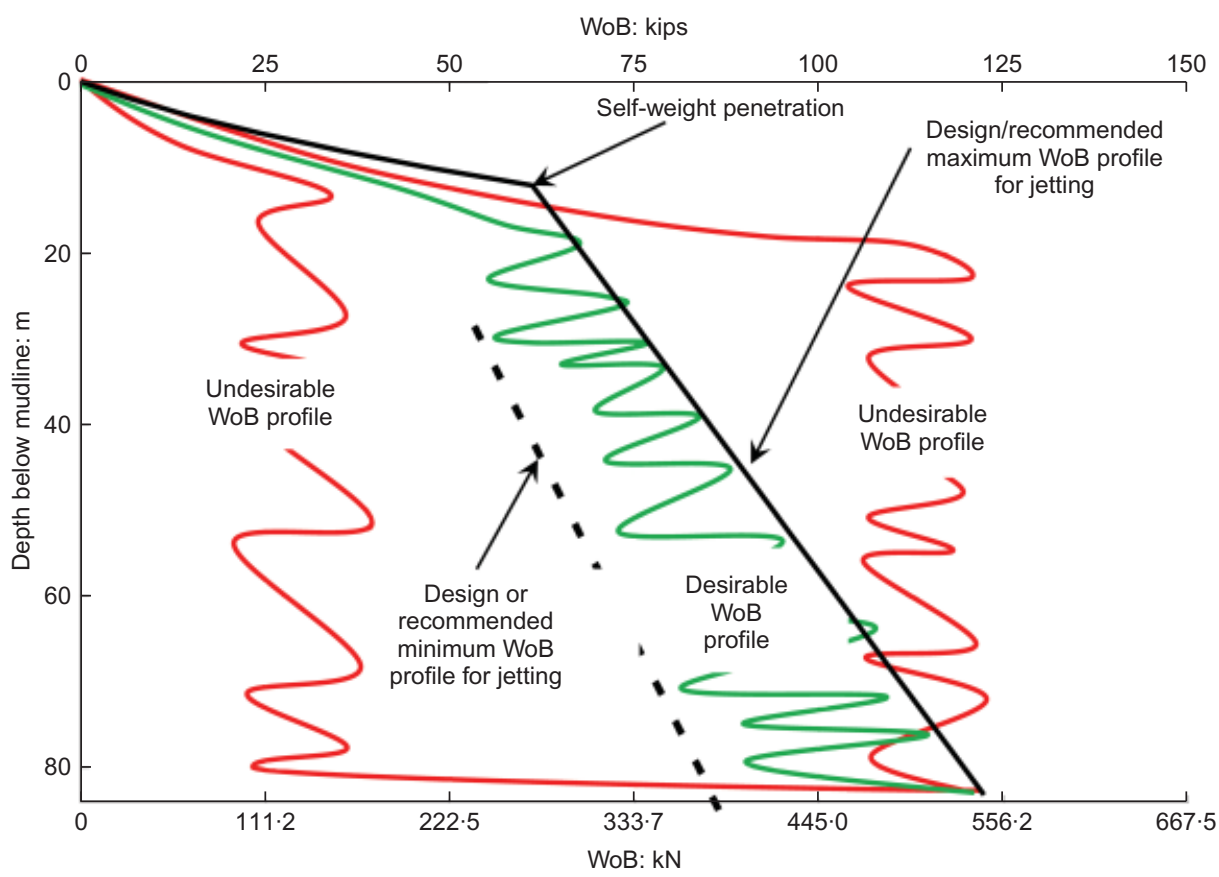

Fig. 4. Examples of weight-on-bit (WoB) profiles: design or recommended, desirable and undesirable 
jetting in deepwater clays (typically with moderate to low yield stress ratio) is a delicate operation that strikes a careful balance between the aforementioned parameters in control (WoB, SSP, flow rate and reciprocations) to achieve the axial bearing capacity needed for the conductor.

\section{AXIAL BEARING CAPACITY OF JETTED CONDUCTORS AND PILES \\ General}

Scientific approaches to pile design have advanced enormously in recent decades and yet, still, the most fundamental aspect of pile design - that of estimating the axial capacity - relies heavily upon empirical correlations (Randolph, 2003). The majority of onshore piles fall into the categories of driven, cast-in-situ bored or screwed-in-place piles. In uniform, dense, granular soils onshore, where pile driving with conventional hammers can be time consuming, jetting may provide a quicker alternative; however, estimation of axial capacity is solely empirical at best, with a wide range of uncertainty, which makes jetting a less attractive option for onshore piles. In the offshore field, extreme geometries - characterised by the length-to-diameter $(L / D)$ ratio - are typically used as individual piles to provide support in tension or compression. The $L / D$ ratio rarely exceeds 60 for thin-walled suction caissons, and for driven piles this ratio is usually less than 60 . With an $L / D$ ratio of typically greater than 60 , jetted conductors differ significantly from conventional offshore piles from the design and installation perspectives.

There are records of jetted piles used to support seabed installations such as manifolds (Humphrey et al., 2010). All the field data indicate the axial capacity of a jetted conductor increases with time during the first 10 days after the installation (Jeanjean, 2002; Akers, 2008), but there is little publicly available information on design, installation records and long-term performance of jetted piles. In general, increases in the axial resistance of a pile after installation have been attributed to the following four factors (Karlsrud, 2012)

(a) dissipation of excess pore pressures and gain in horizontal (radial) effective stress (consolidation)

(b) thixotropy effects

(c) aging effects

(d) multiple unloading and reloading of a pile to near its capacity.

From the above factors, consolidation and aging are known to contribute the most to axial pile capacity (Fakharian \& Attar, 2013), whereas the effects of multiple unloading-reloading are indefinite and difficult to quantify (Karlsrud, 2012), and certainly not studied or taken into account for jetted piles. It should be noted that uncertainty still remains for estimating axial pile capacity after dissipation of excess pore pressures based on existing recommendations for calculation of aging effects (Fellenius, 2008). With respect to thixotropy, Jeanjean (2006) concluded that suction anchors will reach $90 \%$ consolidation after about 30 days in the GoM, when their axial capacity can be estimated using the conventional approaches described in standards (e.g. API RP2A-WSD, API, 2007); however, more data and investigation are needed to confirm the set-up characteristics between 1 and 30 days. Karlsrud (2012) assessed the results from about 15 field load testing programmes carried out over the past 30 years on well-instrumented driven piles and found that the thixotropic effects are strongest while the excess pore pressure dissipation is about $30 \%$ or less. As such, the role of thixotropy was investigated for the jetted piles.

To date, a significant amount of work has been done on the axial capacity of driven piles in clays. Similar to driven piles in soft clays, the reciprocation action in installation of jetted piles causes considerable remoulding in the soil adjacent to the pile surface, with plastic strains extending farther in the radial direction. The imbalance in pore pressures caused by pile installation, jetted or driven, arises from two sources: changes in mean effective stress during shearing and partial remoulding of the soil. In the case of driven piles, the soil outside the immediate vicinity of the pile is displaced outwards with a strain field analogous to cavity expansion in a medium, whereas for jetted piles the soils taken away cause stress relief. In either case, the imbalance in the hydrostatic pore pressure is equilibrated with time mainly through radial consolidation.

Kirby \& Esrig (1979) and Randolph et al. (1979) quantify stress changes due to driven pile installation using the analogy of cylindrical cavity expansion to model the installation of displacement piles. Baligh (1986) pioneered the strain path method and provided more realistic and detailed predictions for the strains and stress changes in the immediate vicinity of the pile, particularly near the tip, but noted that the method may provide inaccurate estimates of the excess pore pressures. Despite the approximations involved in the cylindrical cavity analogue for pile installation, it appears that the general pattern of excess pore pressure, and the consolidation response, can be predicated reasonably for driven piles (Randolph, 2003). Factors such as the length effects, radial stress changes during installation equalisation and loading have also been studied for driven piles in clays, but they are irrelevant to jetted piles.

In summary, the geometry and installation of deepwater jetted piles differ significantly from conventional offshore and onshore deep foundations in soft clays. These differences are reflected in the initial adhesion factors and the setup characteristics of jetted conductors commonly installed for deepwater wells (see following section on 'Estimation of axial capacity'). Furthermore, there is very little literature available on the axial capacity of jetted conductors and there is room for fundamental research on this topic. The work presented herein is a step in that direction. This paper only deals with the consolidation and thixotropic effects associated with the axial capacity of jetted piles, which are thought to play a role in this case.

\section{Estimation of axial capacity}

Lack of published literature, combined with the complex processes involved in the jetting operation, results in an approach for bearing capacity estimation of jetted piles that is heavily dependent on the experience and expertise of the rig-site team. Operators who use jetting technique have developed their own methods. In the 1990s, the jetting practice in the GoM involved using donut weights to enhance the installation. Although successful, the use of donut weights was time-consuming and thus costly for deepwater applications. Jeanjean (2002) described a technique in detail used by BP in deep waters which is solely based on the available $\mathrm{WoB}$ to install conductors within a certain jetting criteria (i.e. reciprocations, flow rates and pressures). The available WoB is typically calculated by adding the buoyed weights of the conductor $\left(W_{\text {Conductor }}\right)$, the wellhead housing $\left(W_{\text {Wellhead }}\right)$, the BHA $\left(W_{\mathrm{BHA}}\right)$ and the drill-ahead tool $\left(W_{\text {Drill-ahead Tool }}\right)$. As such, the immediate axial capacity of the conductor is not controlled by the soil conditions, but rather by the available WoB. Physically, the final WoB represents the last soil resistance measured during installation. Maximising the WoB during jetting is therefore of prime importance. This technique can be mathematically expressed by 


$$
\begin{aligned}
Q_{0} & =\mathrm{WoB}_{\text {Final }} \\
& =R\left(W_{\text {Conductor }}+W_{\text {Wellhead }}+W_{\text {BHA }}+W_{\text {Drill-ahead Tool }}\right)
\end{aligned}
$$

where $Q_{0}$ is the conductor capacity immediately after jetting and $R$ is the WoB utilisation factor between 80 and $100 \%$. The immediate capacity is arbitrarily taken at time $(t)$ equals 0.01 days or $14 \mathrm{~min}$.

The jetting action and reciprocation of the conductor inflicts significant damage to the soil, reducing its strength. This damage is a result of a number of actions: cyclic shearing and remoulding caused by reciprocation, mixing of water at the soil interface and removal of the foundation soil by jetting. The latter causes softening and plastic strains in the soil that radially extend to some distance away from the conductor outer surface. The exact contribution from each of these actions on reducing the soil strength is the subject of further research. The initial adhesions factor $\left(\alpha_{0}\right)$ is calculated by equation (2). Back-analyses of field tests have indicated that the initial adhesion factor could reach as low as 0.03 to 0.07 during and immediately after jetting (Jeanjean, 2002).

$$
\alpha_{0}=\frac{Q_{0}}{\pi D L s_{\mathrm{u}, \mathrm{Ave}}}
$$

The set-up factor at a point in time $\left(\Delta \alpha_{t}\right)$ is then calculated by

$$
\Delta \alpha_{t}=\frac{Q_{t}-Q_{0}}{\pi D L s_{\mathrm{u}, \mathrm{Ave}}}
$$

where $Q_{t}$ is the conductor axial capacity at time equal to $t$. With enough data available at different times, one can establish a function between the time and set-up factor for a particular pile geometry and soil type. Jeanjean (2002) analysed three conductor failures in the GoM and presented the following expression to estimate the set-up as a function of time in days for conductors jetted in deepwater GoM

$$
\Delta \alpha_{\mathrm{GoM}}=0 \cdot 055(2+\log t)
$$

This basically means that the axial capacity of a conductor jetted in the GoM increases $5 \cdot 5 \%$ with decade time from its final WoB. Jeanjean (2002) described the validity of equation (4) to be within the first 10 days after completion of the jetting operation. The work (centrifuge testing and data analysis) presented herein adopts the technique presented in Jeanjean (2002) in an attempt to extend the time limitation inherent in equation (4) while investigating the effects of consolidation and soil thixotropy.

\section{CENTRIFUGE TESTING PROGRAMME \\ Model scaling considerations}

Centrifuge modelling of geotechnical problems is a wellestablished method. The procedures and appropriate scaling laws for geotechnical centrifuge modelling have been given by Taylor (1995) and Garnier et al. (2007). Centrifuge model testing provides data to improve understanding of basic mechanisms of deformation and failure, and provides benchmarks useful for verification of numerical models. See Table 1 for general scaling factors.

A typical conductor pipe in deepwater GoM (0.91 m OD, $38 \cdot 1$ to $50 \cdot 8 \mathrm{~mm}$ thick) is usually jetted to depths of between 60 and $90 \mathrm{~m}$ below the mudline. Most of the axial capacity comes from the bottom one-third of the conductor foundation. As such a $20 \mathrm{~m}$ segment of a $61 \mathrm{~m}$ long jetted conductor was considered appropriate for this study. Spes-
Table 1. General scaling factors for centrifuge tests

\begin{tabular}{l|c|c}
\hline Physical property & Unit & Model scale \\
\hline Gravitation acceleration & $\mathrm{LT}^{-2}$ & $\mathrm{~N}$ \\
Dimension - length and diameter & $\mathrm{L}$ & $1 / \mathrm{N}$ \\
Stress & $\mathrm{ML}^{-1} \mathrm{~T}^{-2}$ & 1 \\
Force & $\mathrm{MLT}^{-2}$ & $1 / \mathrm{N}^{2}$ \\
Velocity & $\mathrm{LT}^{-1}$ & 1 \\
Time-dynamic events & $\mathrm{T}$ & $1 / \mathrm{N}$ \\
Time-consolidation and seepage & $\mathrm{T}$ & $1 / \mathrm{N}^{2}$ \\
Strain & - & 1 \\
Shear strain rate & $\mathrm{T}^{-1}$ & $\mathrm{~N}$ \\
\hline
\end{tabular}

white kaolin clay was selected for the seabed material. Kaolin clay has successfully been used in centrifuge testing for studying various offshore geotechnical engineering settings and processes in the GoM seabed soils (e.g. Andersen \& Jostad, 2004; Jeanjean et al., 2006; Oliviera \& Almeida, 2010; Clukey et al., 2011). Although GoM clay and kaolin clay differ in predominant clay mineral, kaolin clay requires significantly shorter in-flight consolidation time and is more homogeneous in nature, making it more attractive for research purposes.

A gravitation field equal to $73 \mathrm{~g}$ (i.e. $N=73$ ) was selected for the tests based on the availability of steel tubes for model conductor, seabed depth range considered for testing, space on the centrifuge basket for accommodating the test equipment and other model scaling considerations. The jetting time for 60 to $90 \mathrm{~m}$ long conductors in the GoM typically ranges from about 4 to $12 \mathrm{~h}$. The water flow rates and pressures required for jetting conductors in the GoM typically range between about 3028 and $64351 / \mathrm{min}(800$ and 1700 gallon/min) and 8274 and $20684 \mathrm{kPa}$ (1200 and $3000 \mathrm{psi}$ ), respectively. Scaling of soil erosion by jetting action in a geotechnical centrifuge is still a matter of further investigation. Twelve trial tests were conducted on the lab floor for a consolidated kaolin clay sample $\left(\sigma_{\mathrm{p}}^{\prime}=280 \mathrm{kPa}\right.$, similar to the centrifuge stress condition) with different nozzle orifice sizes and arrangements, flow rates and pressures to establish the optimum conditions for conductor installation at $73 \mathrm{~g}$. The results indicated that this can be achieved with flow rates of about 2 to $2.6 \mathrm{1} / \mathrm{min}$ under 1380 to $1724 \mathrm{kPa}$ (200 to $250 \mathrm{psi}$ ) pressure. Fig. 5 illustrates the trial test set-up, model conductor and nozzle.

Difference in the time scaling factors for dynamic events and diffusion (consolidation and seepage) is another important consideration. Shear strain rate in the centrifuge occurs $N$ times faster than the prototype, while diffusion takes place at a rate of $N^{2}$. A penetration rate had to be selected to simulate field conditions while being within the equipment capability. The transition between partially and fully undrained may be evaluated by the normalised velocity defined by (Garnier et al., 2007)

$$
V_{\text {Normalised }}=\frac{\dot{U} d}{c_{\mathrm{V}}}
$$

where $\dot{U}$ is the penetration rate and $d$ is the object diameter. For a normally consolidated clay, $V_{\text {Normalised }}=0.01$ corresponds to fully drained and $V_{\text {Normalised }}=30$ to fully undrained conditions. The kaolin clay used in the centrifuge tests has a $c_{\mathrm{V}}$ value of about $1 \mathrm{~mm}^{2} / \mathrm{s}$ under the stress conditions simulated. A penetration rate of 5 to $6 \mathrm{~mm} / \mathrm{s}$ was determined suitable based on the trial tests, which ensured fully undrained conditions for the centrifuge tests. 

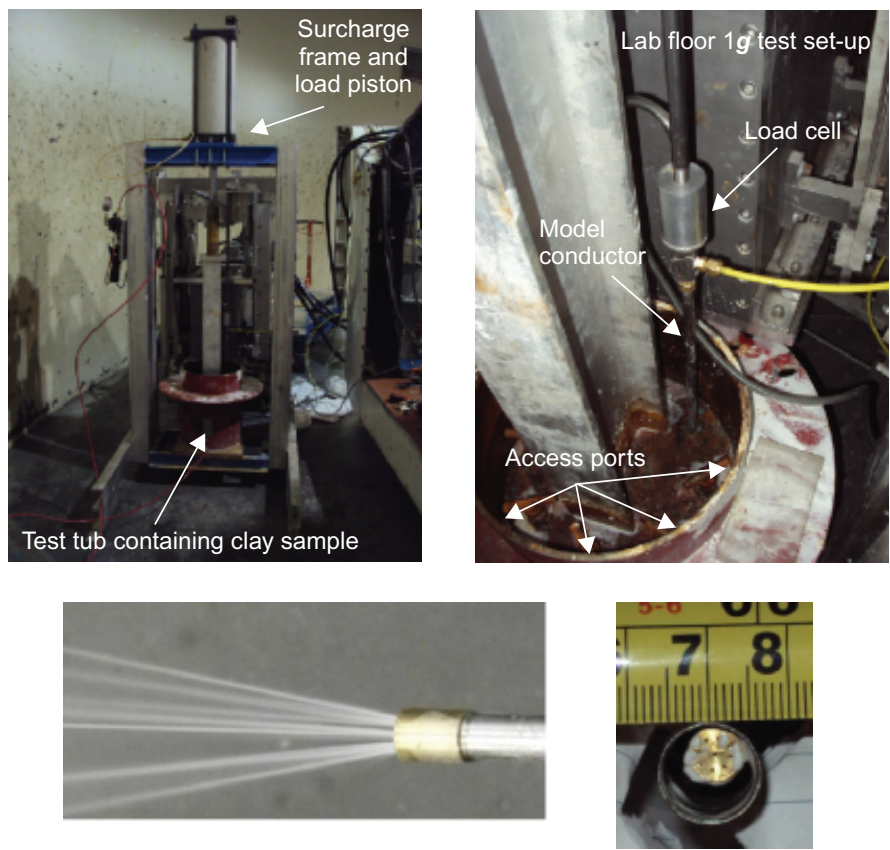

Drill pipe nozzles
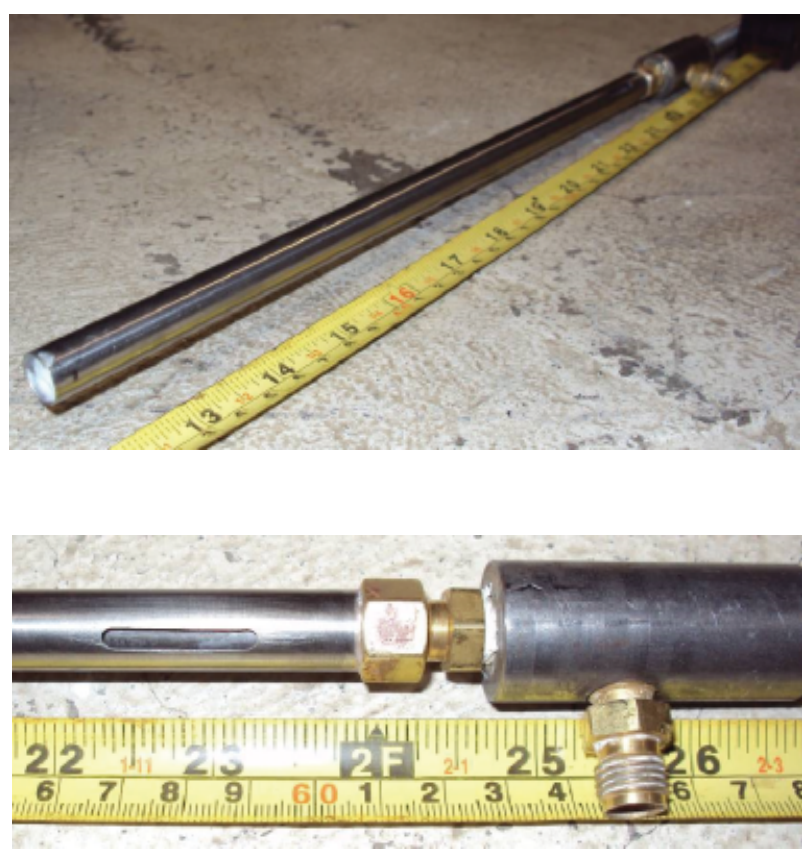

Drill pipe in casing, slotted casing

Fig. 5. Trial test set-up and model conductor

\section{Experimental set-up and procedures}

Figure 6 schematically illustrates the experimental set-up. The test procedures and techniques were developed through 12 simulations conducted on the lab floor (at $1 \mathrm{~g}$ conditions). The centrifuge tests simulated installation of $927 \mathrm{~mm}$ ( 36.5 in) OD conductor jetted in a kaolin clay model seabed condition having a shear strength profile corresponding to the interval from 40.8 to $60.9 \mathrm{~m} \mathrm{(134} \mathrm{to} 200 \mathrm{ft})$ of that

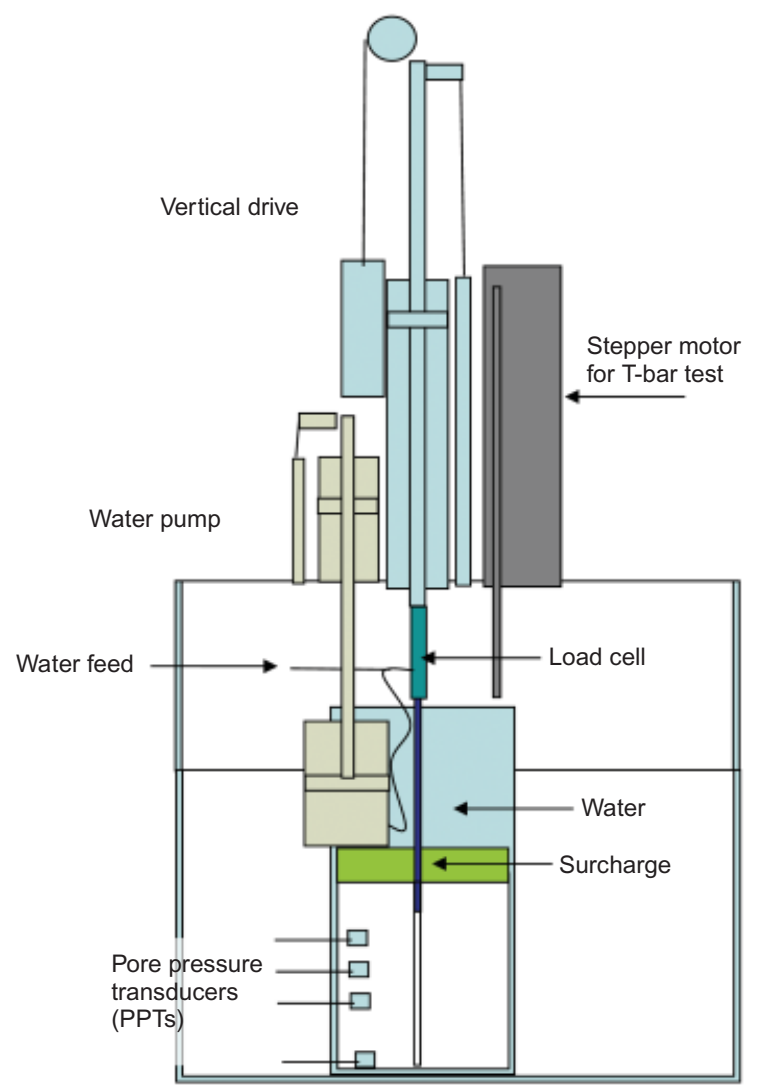

Fig. 6. Schematic diagrams of centrifuge test set-up typical of the GoM. This $20 \cdot 1 \mathrm{~m}$ long section represented approximately the bottom one-third of a $60.9 \mathrm{~m}$ long conductor where most of the axial resistance is obtained. Table 2 summarises the conductor dimensions and Table 3 presents the index properties of the kaolin and GoM clays along with the activity ratios defined as the ratio of plasticity index over percent clay fraction as determined by hydrometer test (Whitlow, 2001). The activity ratio can be used to infer the predominant clay mineral. Although the predominant mineral for GoM clay is illite, compared to kaolinite for the kaolin clay used here, kaolin clay was selected mainly because of its shorter required in-flight consolidation time, while being able to obtain similar shear strength profiles to natural clays.

Table 4 summarises the installation parameters for the tests. The test procedures comprised four stages: T-bar testing to obtain the $s_{\mathrm{u}}$, monotonic push at rate of $4 \mathrm{~mm} / \mathrm{s}$ $(0 \cdot 292 \mathrm{~m} / \mathrm{s}$ in prototype terms $)$ with running pump, jetting with reciprocation, and extraction at equivalent prototype set-up times ranging from 5 days to 1000 days. The nozzle at the tip of the conductor had nine orifices, each $0.35 \mathrm{~mm}$ $(25.55 \mathrm{~mm}$, in prototype terms) in diameter.

A steel plate was placed at the clay surface to produce a surcharge load equal to $280 \mathrm{kPa}$. Predrilled holes in the plate allowed for conductor installation and T-bar testing. Soil consolidation was monitored using two pore pressure transducers (PPTs) and two linear variable differential transducers (LVDTs). A load cell on top of the conductor measured the soil resistance. Fig. 7 compares the $s_{\mathrm{u}}$ measured by a T-bar to the target $s_{\mathrm{u}}$ profile and presents the profile used in the analysis as an average of all the tests. The holes were

Table 2. Centrifuge testing programme, conductor dimensions

\begin{tabular}{l|c|c}
\hline Cross-sectional dimensions & $\begin{array}{c}\text { Model terms: } \\
\mathrm{mm}\end{array}$ & $\begin{array}{c}\text { Prototype terms: } \\
\text { inch }\end{array}$ \\
\hline Outside diameter, OD & $12 \cdot 7$ & $36 \cdot 5$ \\
Inside diameter, ID & $11 \cdot 7$ & $33 \cdot 6$ \\
Wall thickness, $w_{\mathrm{t}}$ & $1 \cdot 0$ & $2 \cdot 87$ \\
\hline
\end{tabular}


Table 3. Index properties of kaolin and Gulf of Mexico (GoM) clays

\begin{tabular}{|c|c|c|c|c|c|c|c|}
\hline Soil & $\begin{array}{c}\text { Moisture content: } \\
\%\end{array}$ & $\begin{array}{c}\text { Liquid limit: } \\
\%\end{array}$ & $\begin{array}{c}\text { Plastic limit: } \\
\%\end{array}$ & $\begin{array}{c}\text { Plasticity index } \\
\text { (PI): \% }\end{array}$ & $\begin{array}{l}\text { Specific } \\
\text { gravity }\end{array}$ & $\begin{array}{l}\text { Clay fraction } \\
\text { (CF): \% }\end{array}$ & $\begin{array}{c}\text { Activity ratio } \\
\mathrm{PI} / \mathrm{CF}\end{array}$ \\
\hline $\begin{array}{l}\text { Kaolin } \\
\text { GoM-batch } 1 \\
\text { GoM-batch } 2 \\
\text { GoM-batch } 3\end{array}$ & $\begin{array}{r}- \\
49 \\
68 \\
108\end{array}$ & $\begin{array}{l}63 \\
81 \\
79 \\
80\end{array}$ & $\begin{array}{l}32 \\
34 \\
31 \\
33\end{array}$ & $\begin{array}{l}31 \\
47 \\
48 \\
47\end{array}$ & $\begin{array}{l}2 \cdot 65 \\
2 \cdot 765 \\
2 \cdot 735 \\
2 \cdot 777\end{array}$ & $\begin{array}{l}76 \cdot 0 \\
66 \cdot 5 \\
65 \cdot 6 \\
64 \cdot 4\end{array}$ & $\begin{array}{l}0.407 \\
0.706 \\
0.732 \\
0.730\end{array}$ \\
\hline
\end{tabular}

Note: the above data were obtained based on ASTM D2216-10 (ASTM, 2010a); ASTM D422-63 (ASTM, 2007); ASTM D4318-10 (ASTM, 2010b); ASTM D854, (ASTM, 2014) procedures.

Table 4. Centrifuge testing programme, test summary

\begin{tabular}{l|c|c|c|c|c}
\hline Test & $\begin{array}{c}\text { Flow rate: } \\
1 / \mathrm{min}\end{array}$ & $\begin{array}{c}\text { Advance rate: } \\
\mathrm{mm} / \mathrm{s}\end{array}$ & $\begin{array}{c}\text { Cycle period } \\
\text { model terms: } \mathrm{s}\end{array}$ & $\begin{array}{c}\text { Amplitude model } \\
\text { terms: mm }\end{array}$ & $\begin{array}{c}\text { Set-up: equivalent } \\
\text { prototype days }\end{array}$ \\
\hline $7-1$ & 1.98 & 6 & 1 & 30 & $5 / 10$ \\
$7-2$ & $2 \cdot 44$ & 5 & $0 \cdot 5$ & 20 & $5 \cdot 3 / 11$ \\
$7-3$ & $2 \cdot 59$ & 6 & 1 & 30 & $9 \cdot 9 / 100$ \\
$7-4$ & $2 \cdot 59$ & 6 & 1 & 30 & $10 / 100 / 1000$ \\
\hline
\end{tabular}

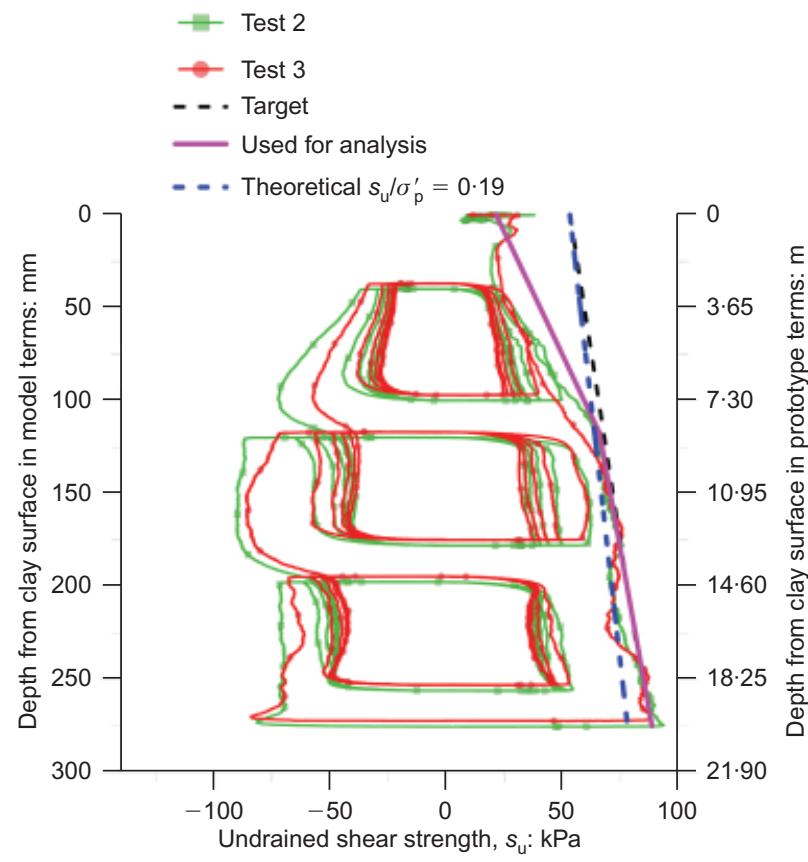

Fig. 7. Centrifuge T-bar test results, undrained shear strength profiles

covered by plugs that were allowed to float and open the hole prior to T-bar testing and conductor jetting. The T-bar was $8 \mathrm{~mm}$ in diameter, $30 \mathrm{~mm}$ long and was pushed at a rate of $3 \mathrm{~mm} / \mathrm{s}$. The T-bar data (resistance to penetration) were converted to $s_{\mathrm{u}}$ using a T-bar factor of $6 \cdot 3$ at the mudline to $4 \mathrm{~mm}$ (i.e. $0 \cdot 5$ times T-bar diameter) that linearly increased to a contact value $10 \cdot 5$ at $20 \mathrm{~mm}$ (model) depth (i.e. $2 \cdot 5$ times the T-bar diameter) and below.

The low strengths measured in the upper $80 \mathrm{~mm}(5.6 \mathrm{~m}$ prototype) are likely caused by the stress relief due to removal of the plugs. An earlier attempt did not use plugs and the test was abandoned shortly after the spin-up because the clay oozed out of the holes. The $s_{\mathrm{u}}$ profile was assumed to increase linearly from below the surcharge plate based on the water contents taken after the tests.

Figure 7 also presents the measured remoulded shear strengths at three depth intervals represented by the cyclic T- bar data. The initial cycles in the middle interval may suggest lower sensitivity compared to the bottom cycles. This is believed to be related to the timing sequence by which the cycle sets were performed. The T-bar was initially pushed at once at $3 \mathrm{~mm} / \mathrm{s}$ and then it was cycled at the same rate starting from the bottom. There was a slight delay in performing the middle cycle and as a result the initial cycles in that set were affected by the strength gain from consolidation.

Figure 8 presents the installation motions in both model and prototype terms. Note the time scale for test $7-4$ is different. The model conductor had a smooth surface to facilitate achieving low adhesion factors during installation, recognising that the set-up resistances would be lower than the field case where the steel is rough. The following difficulties were encountered.

- $\quad$ Test 7-1: the water pressure in the jets dropped to $827 \mathrm{kPa}$ (120 psi), which was significantly lower than 1380 to $1724 \mathrm{kPa}$ (200 to $250 \mathrm{psi}$ ) established in the $1 \mathrm{~g}$ as the pressure needed for jetting soil. As such, the conductor broached in the first $60 \mathrm{~mm}(4.4 \mathrm{~m}$ in prototype terms) of monotonic penetration.

- Test 7-2: the conductor was (at best) slightly in contact with the clay within the upper $60 \mathrm{~mm}$ due to the combined effect of early jetting and pressure relief. However, adjustment of the water pressure from 827 to $1365 \mathrm{kPa}$ (120 to $198 \mathrm{psi}$ ) addressed the broaching issue.

- Test 7-3: the water pressure was increased to $1586 \mathrm{kPa}$ (230 psi) to further improve the jetting, but the flow was prematurely stopped at about $200 \mathrm{~mm}$ (14.6 in prototype terms) depth during the installation due to error in the system control software.

Test 7-4 was the best test and the installation was satisfactorily performed.

\section{Centrifuge test results and discussion}

The data were processed in consideration with the above difficulties and were carefully corrected for end-bearing and the overburden effects. Table 5 summarises the estimated adhesion factors after the installation and set-up as well as the corresponding resistances and shear strengths. It should be noted that the set-up times are taken from the end of installation and are presented in prototype terms. The 
Time, prototype terms: $s$

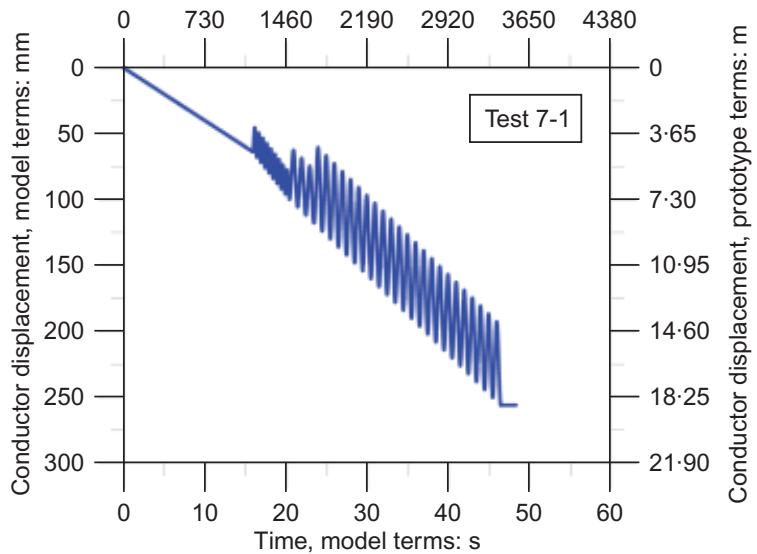

Time, prototype terms: $\mathrm{s}$

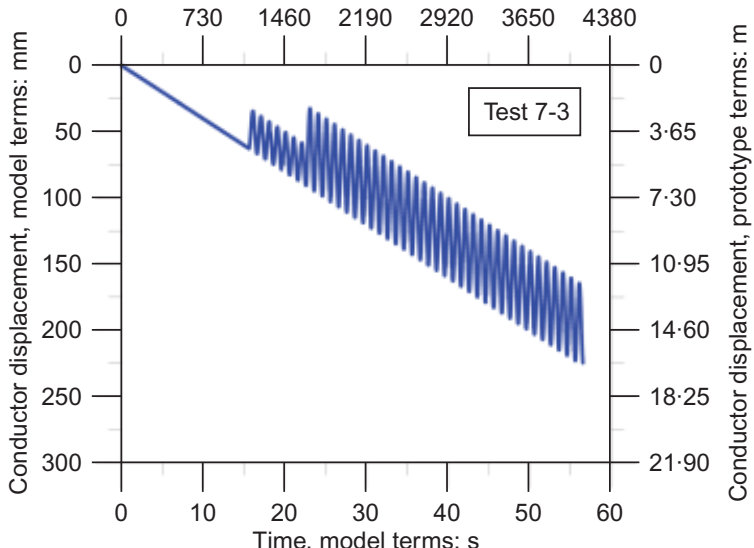

Time, prototype terms: s

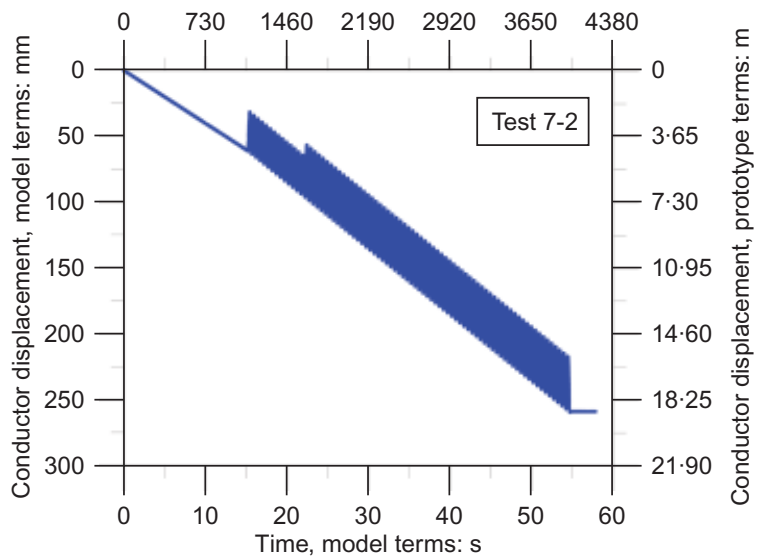

Time, prototype terms: $s$

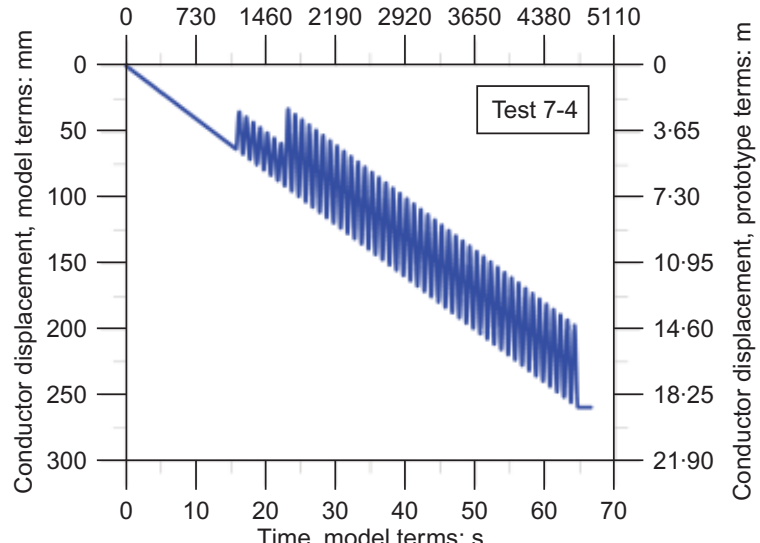

Fig. 8. Centrifuge testing programme, model conductor installation motions

Table 5. Centrifuge testing programme, summary of test results

\begin{tabular}{|c|c|c|c|c|c|c|c|c|c|c|}
\hline \multirow[t]{2}{*}{ Test } & \multirow[t]{2}{*}{ Stage } & \multicolumn{2}{|c|}{ Soil resistance } & \multicolumn{2}{|c|}{ Embedment length } & \multirow[t]{2}{*}{$s_{\mathrm{u}}:{ }^{*} \mathrm{kPa}$} & \multirow[t]{2}{*}{$s_{\mathrm{u}, \text { ave }}: \mathrm{kPa}$} & \multirow{2}{*}{$\begin{array}{l}\text { Estimated } \\
\text { adhesion } \\
\text { factor }^{\dagger}\end{array}$} & \multirow[t]{2}{*}{ Time: days } & \multirow[t]{2}{*}{$\Delta \alpha$} \\
\hline & & Model: N & Prototype: $\mathrm{kN}$ & Model: mm & Prototype: $\mathrm{m}$ & & & & & \\
\hline T7-1 & Installation & $122 \cdot 7$ & 653.9 & $249 \cdot 9$ & $18 \cdot 2$ & $84 \cdot 9$ & $60 \cdot 5$ & $0 \cdot 20$ & $0 \cdot 01-3$ & \\
\hline T7-1 & Extraction 1 & $148 \cdot 4$ & $790 \cdot 8$ & $251 \cdot 9$ & $18 \cdot 4$ & $85 \cdot 2$ & $60 \cdot 7$ & $0 \cdot 24$ & 5 & $0 \cdot 040$ \\
\hline T7-1 & Extraction 2 & $160 \cdot 9$ & $857 \cdot 6$ & $236 \cdot 1$ & $17 \cdot 2$ & $82 \cdot 9$ & $59 \cdot 2$ & $0 \cdot 29$ & 10 & 0.085 \\
\hline $\mathrm{T} 7-2$ & Installation & $73 \cdot 8$ & $393 \cdot 1$ & $258 \cdot 6$ & $18 \cdot 9$ & $86 \cdot 2$ & $53 \cdot 8$ & $0 \cdot 17$ & $0 \cdot 01-3$ & \\
\hline T7-2 & Extraction 1 & $107 \cdot 2$ & $571 \cdot 3$ & $259 \cdot 9$ & $19 \cdot 0$ & $86 \cdot 3$ & $53 \cdot 9$ & $0 \cdot 25$ & $5 \cdot 3$ & 0.076 \\
\hline T7-2 & Extraction 2 & $108 \cdot 3$ & $577 \cdot 0$ & $246 \cdot 7$ & $18 \cdot 0$ & $84 \cdot 5$ & $52 \cdot 2$ & $0 \cdot 28$ & 11 & $0 \cdot 105$ \\
\hline T7-3 & Installation & $79 \cdot 4$ & $423 \cdot 0$ & $214 \cdot 7$ & $15 \cdot 7$ & $79 \cdot 9$ & $57 \cdot 0$ & $0 \cdot 16$ & $0 \cdot 01-3$ & \\
\hline $\mathrm{T} 7-3$ & Extraction 1 & $167 \cdot 2$ & $891 \cdot 2$ & $255 \cdot 5$ & $18 \cdot 7$ & $85 \cdot 7$ & $61 \cdot 1$ & $0 \cdot 27$ & $9 \cdot 9$ & $0 \cdot 106$ \\
\hline $\mathrm{T} 7-3$ & Extraction 2 & $176 \cdot 5$ & $940 \cdot 6$ & $236 \cdot 3$ & $17 \cdot 3$ & $83 \cdot 0$ & $59 \cdot 2$ & $0 \cdot 32$ & 100 & $0 \cdot 154$ \\
\hline T7-4 & Installation & $101 \cdot 6$ & $541 \cdot 4$ & $259 \cdot 2$ & $18 \cdot 9$ & $86 \cdot 2$ & $61 \cdot 4$ & $0 \cdot 16$ & $0 \cdot 01-3$ & \\
\hline T7-4 & Extraction 1 & $174 \cdot 6$ & $930 \cdot 3$ & $260 \cdot 6$ & $19 \cdot 0$ & $86 \cdot 4$ & $61 \cdot 6$ & $0 \cdot 27$ & 10 & $0 \cdot 113$ \\
\hline $\mathrm{T} 7-4$ & Extraction 2 & $174 \cdot 9$ & $932 \cdot 3$ & $235 \cdot 4$ & $17 \cdot 2$ & $82 \cdot 8$ & $59 \cdot 1$ & $0 \cdot 32$ & 100 & $0 \cdot 155$ \\
\hline $\mathrm{T} 7-4$ & Extraction 3 & $214 \cdot 3$ & $1142 \cdot 0$ & $234 \cdot 0$ & $17 \cdot 1$ & $82 \cdot 6$ & $59 \cdot 0$ & $0 \cdot 39$ & 1000 & $0 \cdot 229$ \\
\hline
\end{tabular}

* Undrained shear strength at the conductor shoe.

$\dagger$ Includes the initial adhesions factor, $\alpha_{0}$, and the one after set-up.

installation times require careful consideration. In the field it typically takes about 6 to $12 \mathrm{~h}$ to jet a 60 to $90 \mathrm{~m}$ long conductor. The installations in the centrifuge tests took approximately 3 days (in prototype terms). Thus, some amount of soil set-up may have occurred during the installation. Fig. 9 presents an example of the axial resistances measured during the installation of the fourth conductor and the extraction tests.

In Fig. 9, the actual installation line (grey colour) had to be corrected for the end bearing and the overburden effects for it to represent the net soil resistance on the shaft. The correction was applied to the downward movement only. The end bearing correction was calculated as the product of bearing capacity factor $(\mathrm{Nc}), s_{\mathrm{u}}$ and the cross-sectional area of the conductor and the nozzle. For the overburden correction, it was assumed that the slurry (i.e. cuttings) inside the conductor between the nozzle and opening above the mudline had a submerged unit weight of $2 \cdot 7 \mathrm{kN} / \mathrm{m}^{3}$. Following 


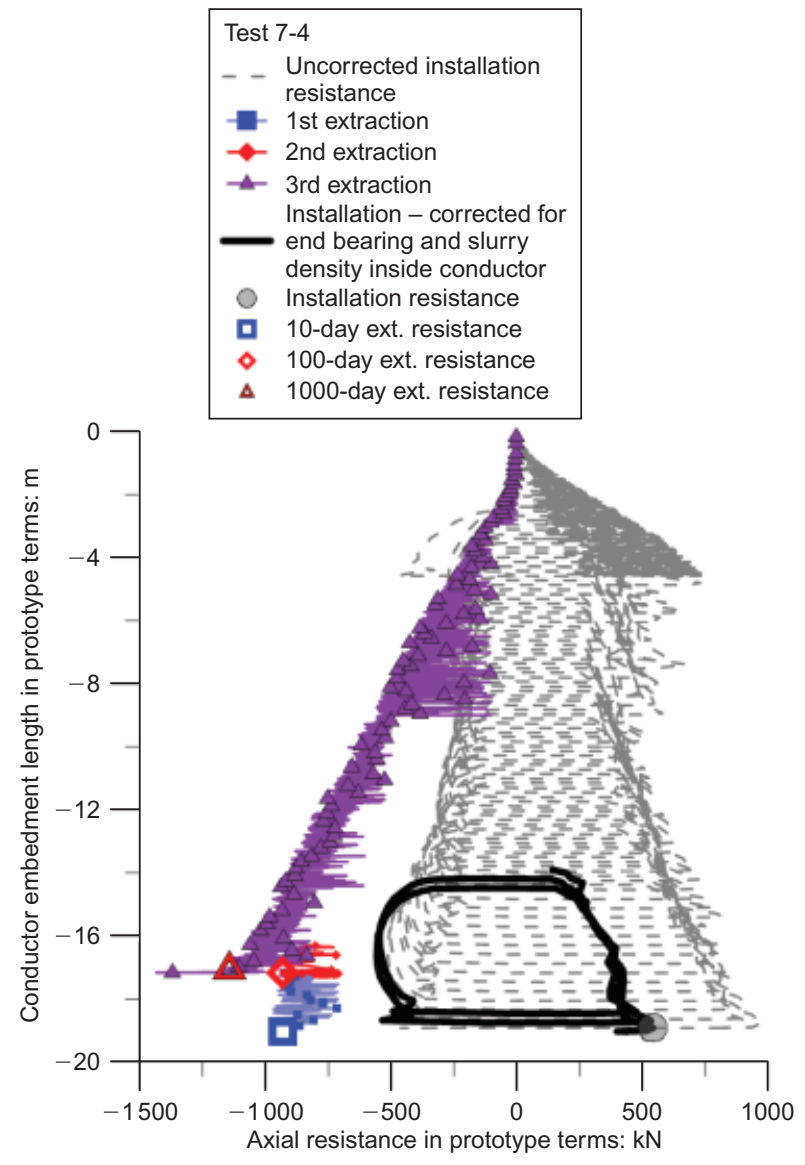

Fig. 9. Test 7-4, axial resistances measured during conductor installation and extraction tests plotted against depth. Note: for the second extraction test, the conductor was pulled out $10 \mathrm{~mm}$ $(0.73 \mathrm{~m}$ in prototype) and then pushed back in to its original depth. Except the uncorrected installation resistance, all other plots represent the shaft resistance (soil resistance on conductor shaft)

these corrections, the resistances from the uplift and penetration at the deepest point of each cycle were approximately the same (corrected shaft resistance in Fig. 9 for the last two cycles), which indicates the appropriateness of the procedures and assumptions made for the correction applied.

The initial adhesion factors, $\alpha_{0}$ values, were estimated using the force measured at the end of the final stroke. The initial adhesion factor, $\alpha_{0}$, in tests 7-2 to 7-4 ranged between $0 \cdot 16$ and $0 \cdot 17$, and for test $7-1$ where the conductor broached, it was $0 \cdot 20$. Fig. 10 plots the estimated total adhesion factors, $\alpha$, against time. The fit through the data is expressed by equation (6).

$$
\alpha=0.085+0.06 \times(2+\log t)
$$

The constant, $0 \cdot 085$, in equation (3) is just an extrapolation of the fit to intercept the $y$-axis at 0.01 days, which corresponds to the normal practice in the field. The second term expresses the rate of increase of the adhesion factor with time, $\Delta \alpha_{t}$. For kaolin clay, $\Delta \alpha_{t}$ increases $6 \%$ per log time. Expectedly, the broaching in test 7-1 affected the fluid-soil-structure interaction mechanism and resulted in higher adhesion factors. The slightly lower water pressure in test 7-2 had a minor effect on the estimated adhesion factors, but the results were nevertheless considered acceptable for inclusion in the curve fitting.

Of particular importance is the scaling associated with loading rate (shear strain rate), motion time and diffusion (consolidation). Given the long duration of simulated centri-

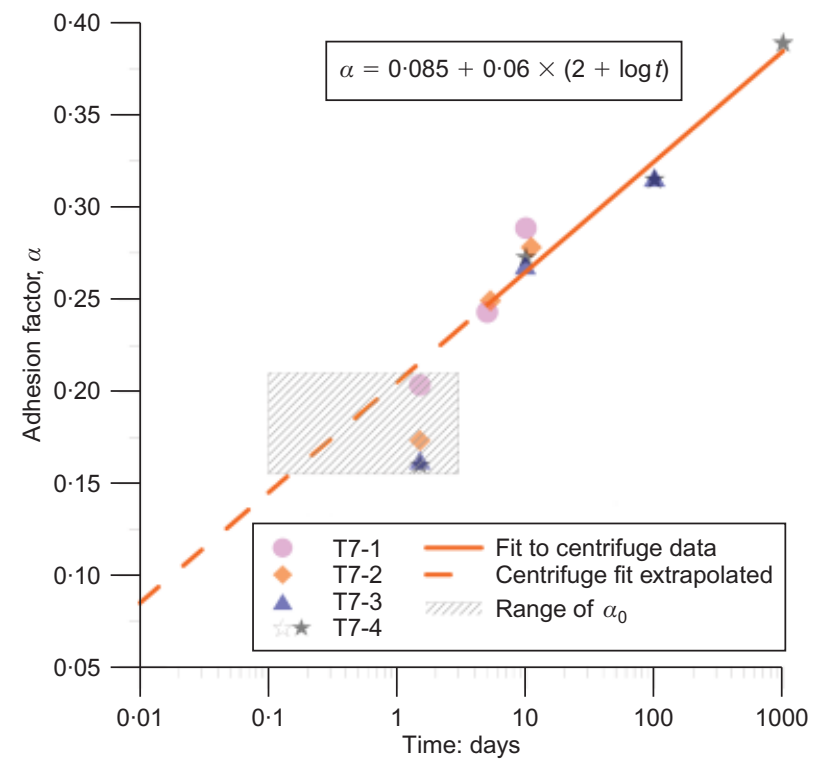

Fig. 10. Adhesion factors estimated from centrifuge tests in kaolin clay

fuge installation compared to the field operation, the $\alpha_{0}$ estimated in the tests could fall anywhere in the hatched area between the $0 \cdot 1$ and 3 days after the installation. The $\alpha_{0}$ data shown correspond to 1.5 days after the installation. It is difficult to surmise the exact end of installation times for each test. However, it is likely that the $\alpha_{0}$ values correspond to earlier times, as 3 days represents an almost drained installation condition. For example, the $\alpha_{0}$ in test 71 may be plotted closer to 1 day given the low pressure and flow rates, and for the others tests, about 0.5 days or less. The time frame for $\alpha_{0}$ in the field is taken at 0.01 days or about $14 \mathrm{~min}$ after installation. In the field, $\alpha_{0}$ typically ranges between about 0.03 and 0.07 . Extrapolation of the centrifuge data to $0 \cdot 01$ days intercepts the $y$-axis at a point within the $\alpha_{0}$ typically encountered in the field. This suggests that the centrifuge tests simulated a similar soil damage as those encountered in the field installations.

It is also important to consider $c_{\mathrm{v}}$, when applying the results presented above to other soil types. See the later section on 'Total and incremental adhesion factors' for the implication regarding deepwater GoM soil.

\section{THIXOTROPY TESTING PROGRAMME}

Thixotropy tests using a miniature laboratory (ASTM D4648-10, ASTM, 2013) were conducted on GoM deepwater clay samples with in-situ moisture contents of around $49 \%, 68 \%$ and $108 \%$ representing deep (40 to $60 \mathrm{~m}$ ), intermediate $(20$ to $40 \mathrm{~m})$ and shallow $(<10 \mathrm{~m})$ depths. Deeper strata contribute much more to the axial bearing capacity than the shallower soils. The containers used for the samples were plastic jars with screw-on lids. The remoulded soil was carefully placed in the jars in small amounts and mixed well until the jar was full. Great care was taken to avoid trapping any air voids in the soil while placing it in the jars during the filling process. Once the jar was full, the date and time were noted on a test $\log$ sheet, the lid was screwed on. The jars were weighed, and electrical tape was wrapped around the lid to help prevent moisture loss, and stored in a temperature-controlled room. After each vane test, the sample moisture content (MC) was measured. The parameters considered in evaluation of thixotropy test results were: shear strength, MC, time and liquidity index (LI). The latter parameter is defined by 


$$
\mathrm{LI}=\frac{w-\mathrm{PL}}{\mathrm{LL}-\mathrm{PL}}
$$

where $w$, LL and PL are the soil moisture content, liquid limit and plastic limit, respectively. The soil is considered in the plastic state when $0<\mathrm{LI}<1 \cdot 0$, and in the liquid state if LI $>1 \cdot 0$. A number of quantitative correlations have been established between LI (or the Atterberg indices) and $s_{\mathrm{u}}$. Equation (8) is an example correlation for the remoulded shear strength of clays (Whitlow, 2001). The constants are model parameters and need to be established for a soil type. However, it can be used as a qualitative assessment tool. In equation (8), a $20 \%$ consistent drop in LI (i.e. reduction in MC due to consolidation) means $28 \%$ increase in shear strength.

$$
s_{\mathrm{u} \_ \text {Remoulded }}=170 \exp (-4.6 \times \mathrm{LI})
$$

Figure 11 presents the shear strengths measured for the nominal $49 \%, 68 \%$ and $108 \%$ MC samples against the MCs and LIs over the course of the thixotropy testing period (i.e. greater than 1000 days). The average LIs for the $49 \%$ sample changed from its initial value of 0.34 and fluctuated between 0.26 and 0.33 (about $25 \%$ change). For the $68 \%$ sample, the average LIs ranged between 0.67 and 0.78 (about $15 \%$ change) with the initial value being $0 \cdot 78$. For the $108 \%$ sample, the average LIs ranged between 1.61 and $1 \cdot 50$, with the initial value being $1 \cdot 61$. Fluctuations in the MCs (also reflected in the LIs) could be attributed to measurement error; however, despite fluctuation the average $\mathrm{MC}$ of each sample remains constant within practical means. With this stated, the shear strengths tend to increase with set-up time. Another way to evaluate the data is to categorise the gains in shear strength based on periods of set-up time (i.e. less than a day, 1 to 5 days, 5 to 10 days, and so on) to investigate the consistency in the data.

Figure 12 presents the same results as Fig. 11, but classified based on the set-up time. The data with the same MC have been grouped for discussion. Group 1 of the $49 \%$ sample (top left) shows strength gain with time, except in the last two time classes. Group 2 shows very little strength gain over the course of more than a year, and Group 3 indicates almost no strength was gained in the $49 \%$ sample the first 2 months and some increase after 2 years. Group 1 of the $68 \%$ sample shows some gain in shear strength in the first 2 months, and nothing afterwards. The second group shows a two-fold increase from the beginning of the tests in the $68 \%$ samples. Group 1 of the $108 \%$ sample shows a systematic increase in the shear strength within the first year,
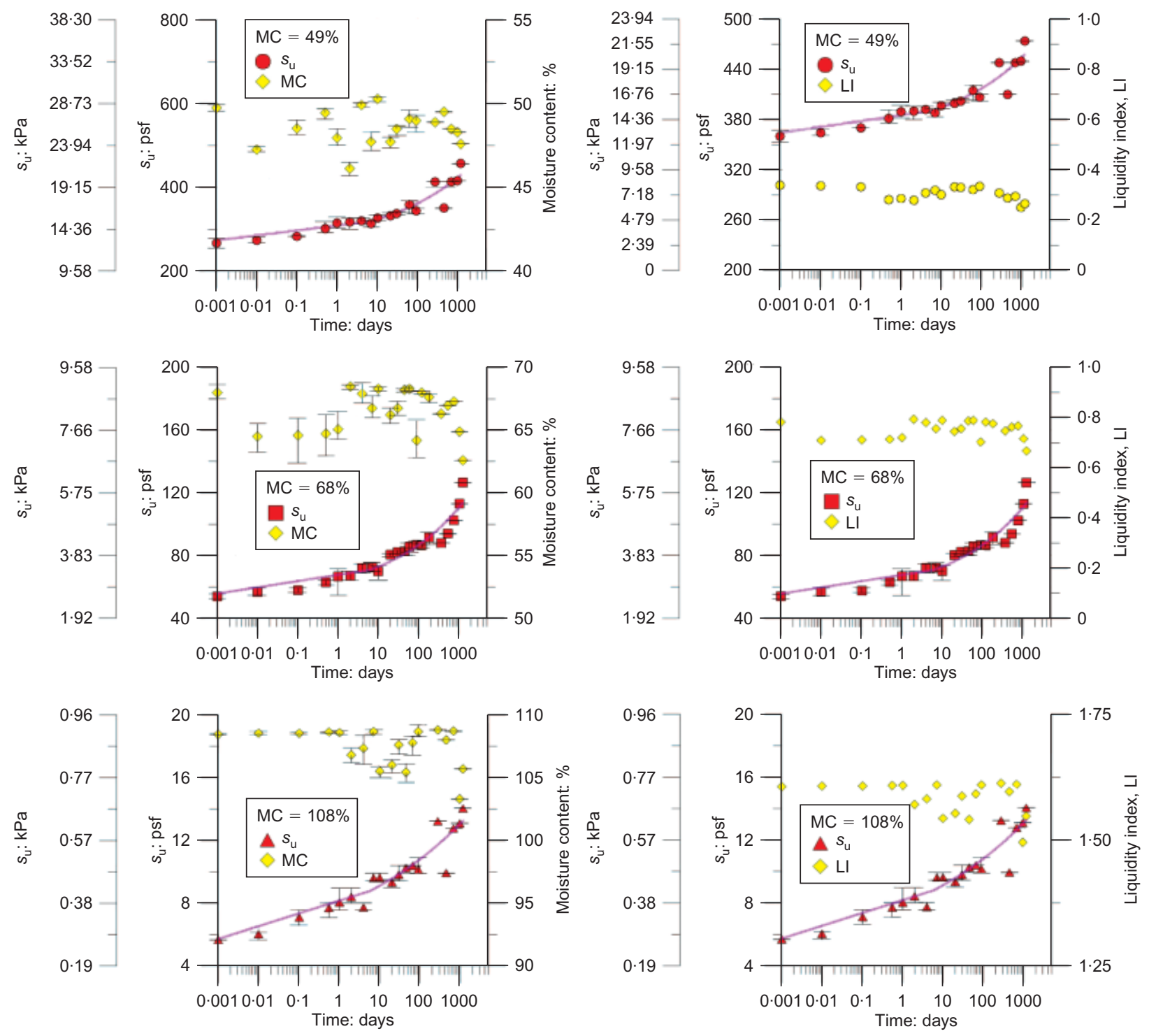

Fig. 11. Thixotropy tests - moisture contents and liquidity indices plotted against shear strength (note the different $y$-axis scales between the figures) 

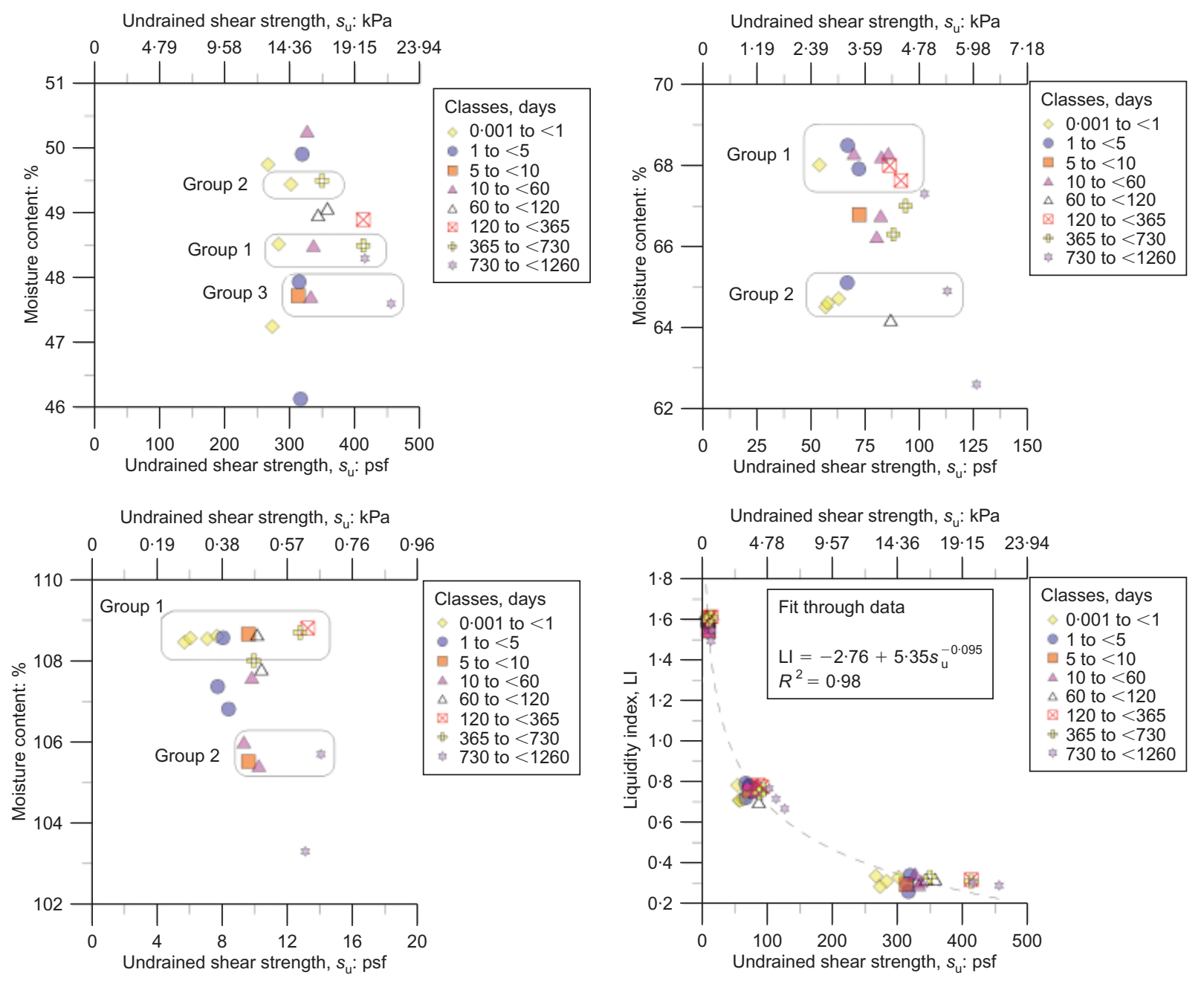

Fig. 12. Thixotropy tests - moisture contents and liquidity indices plotted against shear strength classed based on set-up time

and the same trend may be deduced from Group 2. It should be noted that this strength gain is minor (about $0 \cdot 2 \mathrm{kPa}$ ). Fig. 12, bottom right, plots $s_{\mathrm{u}}$ against LI for the set-up categories. It appears that $s_{\mathrm{u}}$ is a strong function of LI regardless of set-up time, which indicates that a consistent decrease in $\mathrm{MC}$ results in an increase in $s_{\mathrm{u}}$. A trend of increase in $s_{\mathrm{u}}$ with time at constant $\mathrm{MC}$ can be deduced from Fig. 11; however, based on the set-up time classes in Fig. 12 it is difficult to delineate the role thixotropy conclusively. Implications of thixotropy to jetted piles in GoM are discussed below.

\section{IMPLICATIONS FOR GOM FIELD SITUATIONS Thixotropy}

Thixotropic effects have been well recognised to exist in clay suspensions in the realm of fluid mechanics, whereby the clay particles are suspended in the ambient fluid and exhibit visco-plastic behaviour. In geotechnical engineering, such a state typically exists where the MC of a soil is about its liquid limit or higher and, as a result, the effective stresses are minimal. Seng \& Tanaka (2012) investigated the mechanism of the thixotropic phenomenon using a consolidation test with very low pressure in a cell equipped with bender elements. They concluded that, regardless of soil types, the effect of thixotropy was significant around the liquid limit state and less remarkable at the lower and higher ranges. Other factors such as soil mineralogy composition and its activity also contribute to thixotropic strength gain.
The exact role and contribution of each factor (water content, mineralogy, particle size, and so on) are still a matter of further research. Thixotropy has to do with the way clay particles are arranged in the ambient fluid when stationary. Once this structure is disturbed/sheared, the resistance drops (Fig. 13). It is important to note that only a small strain is needed to break this structural bond.

Kaolin clay-water mixtures have proven to show thixotropic behaviour at very low confining pressures (Zakeri et al., 2009), similar to the stress conditions of the thixotropy tests conducted in this programme. However, as the confining stress (or effective stress) increases, thixotropic effects are reduced and consolidation dominates. This can be observed during preparation of kaolin clay samples from slurry to solid state for centrifuge testing. Therefore, the resistances measured during the centrifuge tests are the result of consolidation and not thixotropy. Andersen \& Jostad (2004) investigated mechanisms governing the shear strength along the inside of the skirt wall of suction anchors during and after installation in natural clays and from laboratory tests in kaolin. They also concluded the set-up factor for kaolin differs from natural clays and solely pertains to consolidation.

In natural clays, thixotropy may have an effect on the setup factor, but during the early stages of consolidation. Jeanjean (2006) analysed resistances from installation and retrieval of suction anchors (shortly after installation) in the GoM. He concluded that thixotropy alone appears to provide a good lower bound estimate of ultimate axial capacity, but 

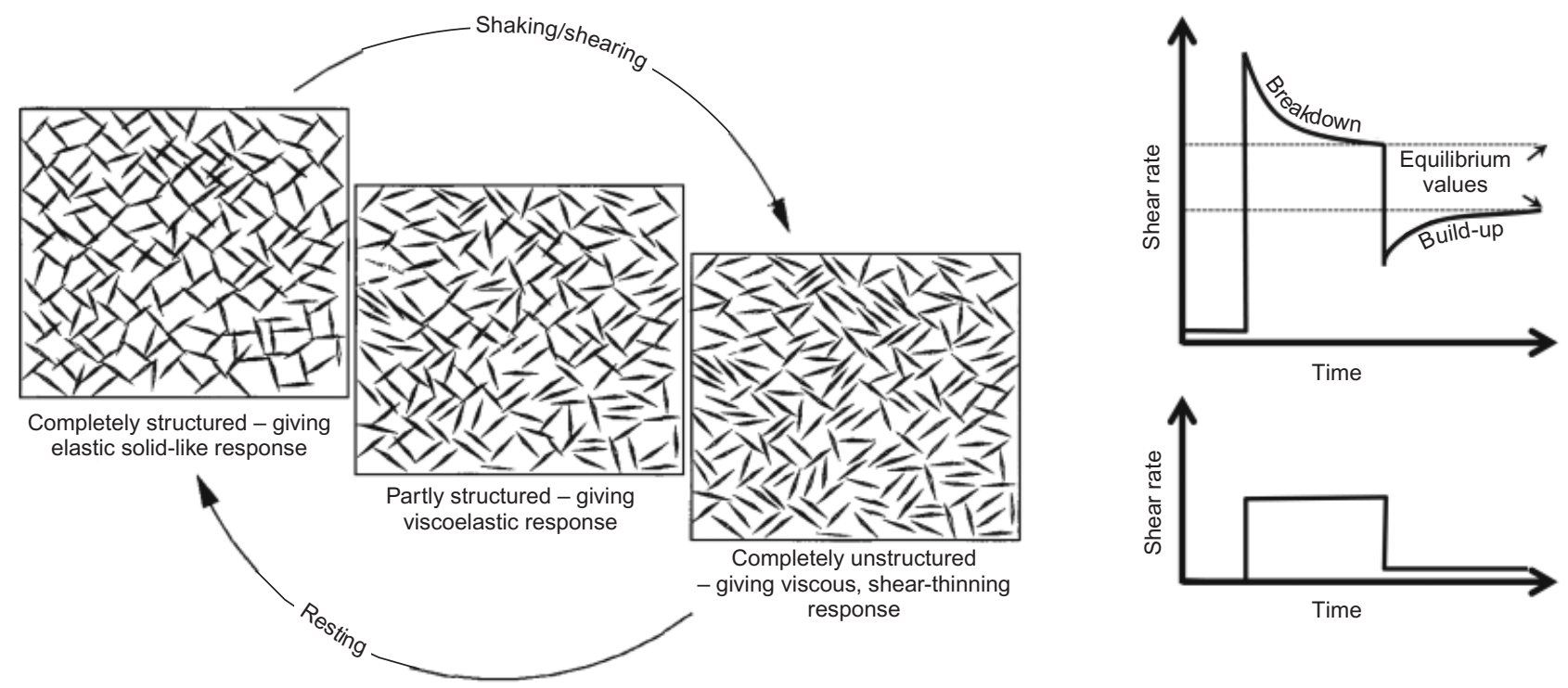

Fig. 13. Breakdown of a three-dimensional thixotropic structure: left adopted from Barnes (1997) and right from Coussot (1997)

the combined effect of the thixotropy and consolidation highly over-estimates the capacity. Karlsrud (2012) has analysed pile load tests from 23 sites over the past 30 years. He concluded that the thixotropy effect may run more or less in parallel with the consolidation (or increase in radial effective stress) up to 30 to $50 \%$ pore pressure dissipation; however, it is difficult to distinguish the effect of thixotropy from consolidation.

Some of the strength gain observed by Jeanjean (2006) in the GoM database shortly after the installation perhaps can be attributed to thixotropy. During that time, the pore pressures adjacent to the pile shaft are high, resulting in very low effective stresses. Thixotropy may play a role during that time, after which, the consolidation effects become dominant. Another way to evaluate the matter is to consider the thixotropy effects with regard to depth along the pile. The thixotropy tests conducted under this programme were designed with field samples to represent the water contents of the seabed soil typically encountered along the pile in the deepwater GoM. It is noted that these tests do not represent the correct stress conditions and, therefore, the strength gain is purely from thixotropic effects and not consolidation. The long-term axial capacity of a pile mainly comes from the contribution of the soils at greater depths, where the MCs are lower and the thixotropy effects are less. The thixotropic tests on the shear strength of the most relevant soil sample (i.e. stronger, $49 \%$ moisture content) increased from $12.8 \mathrm{kPa}$ to $16.6 \mathrm{kPa}$ from 0.01 to 1000 days (Fig. 11, top). This is only about $30 \%$ of the rise seen from pure consolidation strength gain in the centrifuge tests (Fig. 10). Therefore, it appears prudent to exclude thixotropic effects in the design and to estimate the axial capacity of a jetted pile after nearly full set-up. However, thixotropy will be more important for jetted conductors that will be loaded just a few days after installation. It should also be noted that thixotropic properties of soils may vary depending on the composition and mineralogy of clays.

\section{Total and incremental adhesion factors}

Figure 14 compares the $\Delta \alpha_{t}$ values from the centrifuge tests against the GoM database presented by Jeanjean (2002). The fit through the centrifuge data is expressed by

$$
\Delta \alpha_{t_{-} \text {Kaolin }}=0.06 \times(2+\log t)
$$

The set-up times for the GoM data extended to only 6.5 days, the trend of which was described by equation (10), which was validated for 10 days only (Jeanjean, 2002).

$$
\Delta \alpha_{t_{-} \mathrm{GoM}}=0.055 \times(2+\log t)
$$

The $\Delta \alpha_{t}$ values from the centrifuge tests plot below those of the GoM. This is attributed to the smooth surface of the model conductor, which results in approximately $30 \%$ reduction in friction (Bowles, 1996) compared to a rough steelsoil interface (i.e. the results represent the lower bound values). Nonetheless, the centrifuge test results provide the following two major insights.

(a) The axial capacity of a jetted pile continues to increase with time within at least the first 1000 days following the installation.

(b) The rate of increase for both the GoM field tests and the centrifuge tests follow a power law.

Figure 15 compares the total adhesion factor values from the centrifuge tests and the GoM data. It includes equation (6), and equation (10) shifted upwards by 0.05 (typical $\alpha_{0}$ values) and extrapolated to 1000 days. To extend the centrifuge results to the GoM clay, it is necessary to consider the difference between the $c_{\mathrm{V}}$ values of the kaolin and GoM clays and correct the set-up times accordingly. The kaolin $c_{\mathrm{V}}$ was $1 \mathrm{~mm}^{2} / \mathrm{s}$ under the stress conditions simulated. To demonstrate implications of the centrifuge test results to GoM, a $c_{\mathrm{V}}$ value of $0.063 \mathrm{~mm}^{2} / \mathrm{s}\left(2 \mathrm{~m}^{2} /\right.$ year $)$ was selected. This value was obtained from consolidation tests on a GoM clay sample under stress conditions corresponding to the depth of interest, which is deeper than those typically considered for conventional foundations. It should be noted that soil properties may vary widely across the deepwater GoM (e.g. Quirós \& Little, 2003). The $c_{\mathrm{v}}$ value used here is only for purposes of demonstration; however, it is not uncommon to encounter such an average value at about $60 \mathrm{~m}$ soil depth in deepwater GoM. In order to correct for the difference in $c_{\mathrm{V}}$, the centrifuge set-up times need to be corrected for the ratio of the $c_{\mathrm{V}}$ values, which is about $15 \cdot 77$, to represent that of the GoM clay. The corrected set-up times are shown in Fig. 15, and the fit through the data is expressed by 


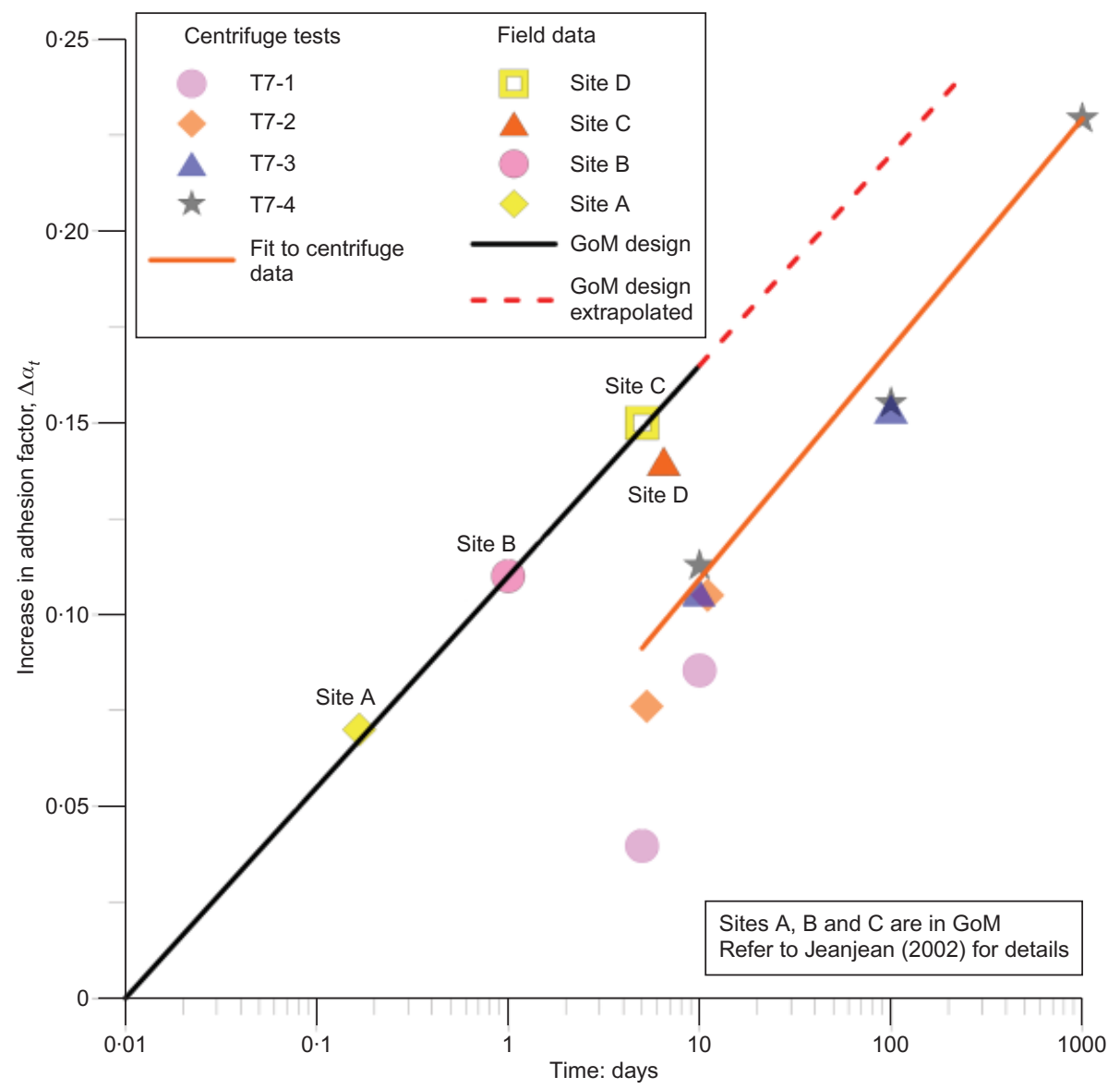

Fig. 14. Comparison of $\Delta \alpha_{t}$ values from the centrifuge tests and the GoM database

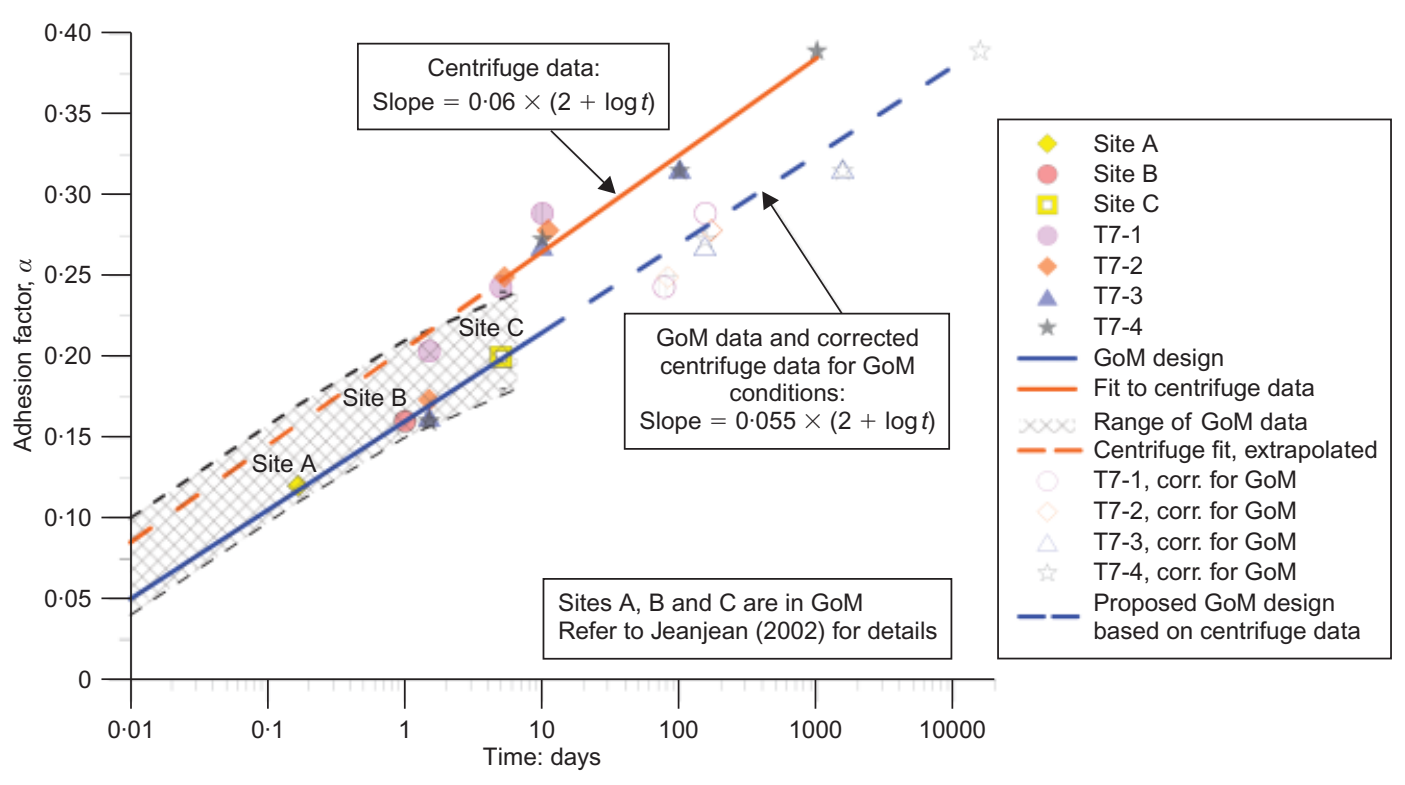

Fig. 15. Comparison of total adhesion factors, $\alpha$ - centrifuge tests and GoM data

$$
\alpha_{\text {GoM, Power-law Fit }}=0.05+0.055 \times(2+\log t)
$$

The second term of equation (11) describes the rate of increase in the adhesion factor per decade time, while the first term shows the intercept with the $y$-axis. Equation (10) provides a lower bound estimate for the adhesion factor serving as an interim relationship until additional data are collected using actual GoM soil. It should be noted that the centrifuge data corrected for the difference in the $c_{\mathrm{v}}$ values tend to follow the extrapolated GoM design line.

\section{CONCLUSIONS}

The results provided valuable insights into the soilstructure mechanism and set-up characteristics of jetted conductors potentially used as piles. The centrifuge tests 
reasonably simulated typical field installation processes and conditions. If the trend of the adhesion factor is extrapolated to 0.01 days, the $\alpha_{0}$ values measured in the centrifuge tests will fall within the range of those obtained in the field. The set-up characteristics in the centrifuge tests followed a power-law relationship. Kaolin clay has successfully been used in numerous studies to simulate the soil-structure interaction mechanisms in engineering problems. Therefore, the set-up characteristic of the GoM clay is most likely to follow a similar power-law relationship. In the absence of further model testing using actual GoM soil, the following expression could provide an estimate of the axial capacity of a jetted pile for set-up times greater than 10 days:

$$
\Delta \alpha_{t_{-} \mathrm{GoM}}=0.055 \times(2+\log t) \text { when } t<1000 \text { days }
$$

Equation (12) provides a lower bound estimate of the setup. The centrifuge tests used a smooth surface model conductor, which considerably reduces the skin friction.

The results of the thixotropy study do not appear to offer a significant contribution for piles with long consolidation times. Thixotropy may play a role during the early stages of set-up when the radial effective stresses are quite low. Thixotropy may be significant for jetted conductors, but not for jetted piles where the long-term capacity is considered with more than $30 \%$ dissipation of pore pressures. Further, thixotropic strength drops significantly once the structural bonds between the particles are broken. There is uncertainty with respect to the strain level required to break the thixotropic bonds compared to that required to fully mobilise soil undrained shear strength. This uncertainty is further compounded by the lack of clear understanding of thixotropic strength at high confining stresses and its relation to degree of consolidation. Therefore, the thixotropy effects should be excluded in estimation of axial capacity of jetted piles. Equation (12) can also be used to re-assess the axial capacity of the existing jetted piles. At the end, conducting additional centrifuge tests using actual GoM clay is highly recommended to confirm the above conclusions and to further study the set-up characteristics.

\section{ACKNOWLEDGEMENTS}

The authors would like to acknowledge the sterling efforts of the professional staff at C-CORE and C \& C Technologies Survey Services for conducting the centrifuge and thixotropy tests, respectively.

\section{NOTATION}

$c_{\mathrm{V}}$ consolidation coefficient of soil

$D$ conductor outside diameter

$d$ object diameter

$L$ conductor embedded length

$\mathrm{Nc}$ bearing capacity factor equal to $7 \cdot 5$

$Q_{0}$ conductor capacity immediately after jetting

$Q_{t}$ conductor capacity at time $t$ (days) after jetting

$R$ weight-on-bit utilisation factor, between 80 and $100 \%$

$s_{\mathrm{u}} \quad$ undrained shear strength of soil

$s_{\mathrm{u}, \text { Ave. }} \quad$ average undrained shear strength of soil over the conductor embedded length

$t$ time (days)

$\dot{U}$ penetration rate

$W_{\mathrm{BHA}}$ buoyed weight of bottom-hole assembly

$W_{\text {Conductor }}$ buoyed weight of surface conductor

$W_{\text {Drill-ahead Tool }}$ buoyed weight of drill-ahead tool

$W_{\text {Wellhead }}$ buoyed weight of wellhead housing

$w$ soil moisture content

$\alpha$ adhesion factor

$\alpha_{0}$ initial adhesion factor or adhesion factor immediately after jetting

\author{
$\Delta \alpha$ set-up factor as a function of time $t$ \\ $\Delta \alpha_{\mathrm{GoM}}$ set-up factor as a function of time $t$ for Gulf of \\ Mexico \\ $\Delta \alpha_{t}$ set-up factor at time $t$ \\ $\sigma_{\mathrm{p}}^{\prime} \quad$ pre-consolidation stress
}

\section{REFERENCES}

Akers, T. J. (2008). Jetting of structural casing in deepwater environments: job design and operational practices. SPE Drilling and Completion 23, No. 1, 102378-PA.

Andersen, K. H. \& Jostad, H. P. (2004). Shear strength along inside of suction anchor skirt wall in clay. Proceedings of the offshore technology conference, Houston, TX, paper OTC 16844.

API (American Petroleum Institute) (2007). API RP2A-WSD: Recommended practice for planning, designing and constructing fixed offshore platforms - working stress design, American Petroleum Institute Recommended Practice 2A-WSD (RP 2AWSD), 21st edn. Washington D.C., USA: American Petroleum Institute.

ASTM (2007). ASTM D422-63: Standard test for particle size analysis of soil. West Conshohocken, PA, USA: ASTM International.

ASTM (2010a). ASTM D2216-10: Standard test methods for laboratory determination of water (moisture) content of soil and rock by mass. West Conshohocken, PA, USA: ASTM International.

ASTM (2010b). ASTM D4318-10: Standard test methods for liquid limit, plastic limit, and plasticity index of soils. West Conshohocken, PA, USA: ASTM International.

ASTM (2013). ASTM D4648-10: Standard test method for laboratory miniature vane shear test for saturated fine-grained clayey soils. West Conshohocken, PA, USA: ASTM International.

ASTM (2014). ASTM D854: Standard test methods for specific gravity of soil solids by water pycnometer. West Conshohocken, PA, USA: ASTM International.

Baligh, M. M. (1986). Undrained deep penetration, I: shear stresses Géotechnique 36, No. 4, 471-485, http://dx.doi.org/10.1680/ geot.1986.36.4.471.

Barnes, H. A. (1997). Thixotropy - a review. Journal of NonNewtonian Fluid Mechanics 70, No. 6, 1-33

Bowles, J. E. (1996). Foundation analysis and design. New York, NY, USA: McGraw-Hill.

Clukey, E. C., Tognarelli, M. A., Li, G., Ghosh, R., Phillips, R., Zakeri, A., Elliott, B. J., Bhattacharyya, A. \& Sun, Q. (2011). Simulation of SCR behavior at touchdown zone - Part II: testing of a sectional SCR model in a geotechnical centrifuge. Proceedings of the offshore technology conference, Rio de Janeiro, Brazil.

Coussot, P. (1997). Mudflow rheology and dynamics. Rotterdam, the Netherlands: Balkema.

Evans, T. G., Feyereisen, S. \& Rheaume, G. (2002). Axial capacities of jetted well conductors in Angola. In Offshore site investigation and geotechnics: diversity and sustainability. London, UK: The Society for Underwater Technology.

Fakharian, K. \& Attar, I. H. A. S. H. H. (2013). Contributing factors on soil setup and the effects on pile design parameters. In Proceedings of the 18th international conference on soil mechanics and geotechnical engineering, Paris, France (eds P. Delage, J. Desrues, R. Frank, A. Puech and F. Schlosser). RueilMalmaison, France: Comité Français de Mécanique des Sols et de Géotechnique.

Fellenius, B. H. (2008). Effective stress analysis and set-up for shaft capacity of piles in clay. In Honoring John Schmertmann: From research to practice in geotechnical engineering (eds J. E. Laier, D. K. Crapps and M. H. Hussein). Reston, VA, USA: American Society of Civil Engineers (ASCE).

Garnier, J., Gaudin, C., Springman, S. M., Culligan, P. J., Goodings, D., Konig, D., Kutter, B., Phillips, R., Randolph, M. F. \& Thorel, L. (2007). Catalogue of scaling laws and similitude questions in centrifuge modelling. International Journal of Physical Modelling in Geotechnics 7, No. 3, 1-24.

Humphrey, G. D., Tjok, K.-M., Yang, L. \& Fourchy, P. J. (2010). Supporting subsea structures with jetted piles saves time, cost in deepwater Gulf of Mexico. Drilling Contractor 2010, May/June, 60-64. 
Jeanjean, P. (2002). Innovative design method for deepwater surface casings (SPE 77357). In Proceedings of the SPE annual technical conference and exhibition. San Antonio, TX, USA: Society of Petroleum Engineers.

Jeanjean, P. (2006). Set-up characteristics of suction anchors in soft Gulf of Mexico clays: experience from field installation and retrieval. Proceedings of the offshore technology conference, Houston, TX, paper OTC 18005.

Jeanjean, P., Znidarcic, D., Phillips, R., Ko, H. Y., Pfister, S., Cinicioglu, O. \& Schroeder, K. (2006). Centrifuge testing on suction anchors: double-wall, overconsolidated clays, and layered soil profile. Proceedings of the offshore technology conference, Houston, TX, paper OTC 18007.

Karlsrud, K. (2012). Predication of load-displacement behaviour and capacity of axially loaded piles in clay based on analyses and interpretation of pile load test results. $\mathrm{PhD}$ thesis, Norwegian University of Science and Technology, Trondheim, Norway.

Kirby, R. C. \& Esrig, M. I. (1979). Further development of a general effective stress method for prediction of axial capacity for driven piles in clay. In Proceedings of conference on recent developments in the design and construction of piles (ed. E. De Beer). London, UK: Institution of Civil Engineers (ICE).

Minton, R. C. (1967). Review of procedures after four years experience in floating drilling. J. Petroleum Technol. 19, No. 2, $167-174$.

Oliviera, J. R. M. S. \& Almeida, M. S. S. (2010). Pore-pressure generation in cyclic T-bar tests on clayey soil. Int. J. Phys. Modelling Geotech. 10, No. 1, 19-24.

Quirós, G. W. \& Little, R. L. (2003). Deepwater soil properties and their impact on the geotechnical program. Proceedings of the offshore technology conference, Houston, TX, paper OTC 15262.

Randolph, M. F. (2003). 43rd Rankine Lecture: Science and empiricism in pile foundation design. Géotechnique 53, No. 10, $847-$ 875, http://dx.doi.org/10.1680/geot.2003.53.10.847.

Randolph, M. F., Carter, J. P. \& Wroth, C. P. (1979). Driven pile in clay - the effects of installation and subsequent consolidation. Géotechnique 29, No. 4, 361-393, http://dx.doi.org/10.1680/ geot.1979.29.4.361.

Seng, S. \& Tanaka, H. (2012). Properties of very soft clays: a study of thixotropic hardening and behavior under low consolidation pressure. Soils Found. 52, No. 2, 335-345.

Taylor, R. N. (1995). Geotechnical centrifuge technology. London, UK: Blackie Academic and Professional.

Whitlow, R. (2001). Basic soil mechanics. Harlow, UK: Prentice Hall.

Zakeri, A., Si, G., Marr, J. D. G. \& Hoeg, K. (2009). Experimental investigation of subaqueous clay-rich flows, generated turbidity and sediment deposition. In Submarine mass movements and their consequences: proceedings of the 4th international symposium, Austin, Texas (eds D. C. Mosher, R. C. Shipp, L. Moscardelli, J. D. Chaytor, C. D. P. Baxter, H. J. Lee and R. Urgeles), pp. 95-106. Dordrecht, the Netherlands: Springer. 